\title{
CLASSIFICAÇÃO ALOESTRATIGRÁFICA DO QUATERNÁRIO SUPERIOR NA REGIÃO DE BANANAL (SP/RJ)
}

\author{
JOSILDA R.S. MOURA* \& CLÁUDIO L. MELLO*
}

\begin{abstract}
UPPER QUATERNARY ALLOSTRATIGRAPHIC CLASSIFICATION IN BANANAL REGION (SP/RJ), BRAZIL. Detailed stratigraphic studies, trying to distinguish allostratígraphic units, have allowed the ordenation of late Quaternary deposits found in Bananal region (SP/RJ) through identification of regional discontinuities. The characterization of these discontinuities, essential to understand evolutional dynamics, is based on stratigraphic and geomorphological arguments. The first regional records of Quaternary sedimentation correspond to colluvial deposits named Santa Vitória and Rio do Bananal alloformations. The latter preserves a paleohorizon A, dated in approximately 10.000 years (Pleistocene/Holocene boundary). The first Holocene sediments are fluvial-lacustrine organic clayey deposits called Rio das Três Barras Alloformation, dated in approximately 9.500 years. Following that, another phase of colluviation (Cotiara Alloformation) and a fluvial sandy sequence (Rialto Alloformation) are documented. In clear erosive unconformity above subjacent units, the Manso Alloformation gathers deposits characterized by a great sedimentologic heterogeneity; it contains three facies (Campinho, Quebra-Canto and Fazendinha) closely interfingered. The following sequence of events records an intercalation of colluvial deposits (Piracema and Carrapato alloformations), responsible for recent landscape reworking, and fluvial deposits (Resgate Alloformation), proving other fluvial aggradation phase. The identified deposits represent alternated and/or contemporary events of integrated slopes and streams dynamics that probably transcends Bananal region $(\mathrm{SP} / \mathrm{RJ})$.
\end{abstract}

Keywords: Quaternary, geomorphic evolution, allostratigraphy, slope deposits, alluvial deposits, discontinuities.

\begin{abstract}
RESUMO Uma análise estratigráfica detalhada, como tentativa para a adoção de unidades aloestratigráfícas, permitiu a ordenação dos depósitos neoquaternários encontrados na região de Bananal (SP/RJ), a partir da identificação de descontinuidades regionais, cuja caracterização, indispensável ao entendimento da dinâmica evolutiva, baseia-se em argumentos estratigráfícos e geomorfológicos. Os primeiros registros da sedimentacão quaternária reconhecidos regionalmente correpondem a depósitos coluviais, reunidos sob as denominações Aloformação Santa Vitória e Rio do Bananal, esta última preservando um paleo-horizonte A, datado em aproximadamente 10.000 anos (limite Pleistoceno/Holoceno). A sedimentação holocênica é inicialmente registrada nos depósitos argilosos, orgâniços, de origem flúvio-lacustre, da Aloformação Rio das Três Barras, datados em aproximadamente 9.500 anos. É documentada, a seguir, uma nova fase de coluviação (Aloformação Cotiara) e uma seqüência arenosa de origem fluvial (Aloformação Rialto). Em nítida discordância erosiva sobre as unidades subjacentes, a Aloformação Manso engloba depósitos sedimentologicamente bastante diversos, apresentando três associações de fácies (Campinho, Quebra-Canto e Fazendinha) interdigitadas. A seqüência de eventos registra, a seguir, intercalação entre depósitos coluviais (Aloformações Piracema e Carrapato), responsáveis pelo reafeiçoamento recente da paisagem, e fluviais (Aloformação Resgate), testemunhos de uma nova fase de agradação fluvial. Os depósitos identificados representam eventos alternados e/ou contemporâneos da dinâmica integrada das encostas e fluxos canalizados, que provavelmente transcendem a região de Bananal (SP/RJ).
\end{abstract}

Palavras-chaves: Quaternário, evolução geomorfológica, aloestratigrafia, depósitos de encosta, depósitos aluviais, descontinuidades.

INTRODUĈ̃̃O O reconhecimento estratigráfico dos depósitos sedimentares quaternários, especialmente dos depósitos continentais, tem representado um desafio pela falta de metodologias que os distingam com a necessária precisão, considerando o caráter descontínuo e irregular do registro sedimentar quartenário e os curtos intervalos de tempo geológico envolvidos. Como reconhecido por Bowen (1978), os interessados nos estudos do Quaternário devem lidar com detalhamento e precisão temporal desconhecidos para os demais períodos de tempo geológico.

$\mathrm{Se}$, por um lado, os depósitos quaternários propiciam, em geral, interpretação relativamente fácil da gênese e do ambiente, por outro lado, dificultam o estabelecimento da litoestratigrafia, pelas freqüentes similaridades e recorrência de fácies e por ocorrerem distribuídos irregularmente sob as múltiplas formas de relevo, ou seja, geograficamente descontínuos. Faltam, além disso, na maioria dos casos, dados geocronológicos precisos. Dessa maneira, resultam ser pouco aplicáveis os métodos estratigráficos usados para as seqüências sedimentares mais antigas.

A necessidade de abordagem especial já era reconhecida por Fairbridge (1968), que, apesar de considerar os problemas da Estratigrafia do Quaternário essencialmente similares àqueles de outros tempos geológicos, admitia que as técnicas e métodos a serem utilizados para resolvê-los deveriam ser bastante diferentes.

A obtenção de um enfoque metodológico mais específico à análise estratigrafica de seqüências sedimentares quaternárias, e à conseqüente identificação de paleoambientes em períodos recentes, não pode prescindir do conhecimento das diversas situações de organização das paisagens - relação Gecmorfologia/Estratigrafia (Paepe, inédito). Se não consideradas em posições complementares, a significativa descontinuidade espacial dos depósitos quaternários frustra qualquer tentativa de adoção exclusiva de critérios estratigráficos convencionais, assim como evidências morfológicas são, por si só, insuficientes para a detecção de todas as unidades elaboradas em fases sucessivas de erosão e deposição.

Nesse sentido, a visão morfoclirnática, adotada por Bigarella \& Andrade (1965) e Bigarella et al (1965) nos estudos do Quaternário brasileiro, embora atualmente reconhecida como de difícil aplicação (Mendes 1984), representou um avanço importante nos estudos da Estratigrafia do Quaterná- 
rio, associando à identificação de superfícies erosivas a caracterização de seus depósitos correlativos.

Frye \& Willman (1962) propuseram unidades informais, denominadas morfoestratigráficas, que determinam corpos sedimentares identificáveis primariamente pela forma apresentada em superfície, os quais podem ser distingüidos ou não pela litologia e/ou pela idade das unidades adjacentes. Meis (1977) aplicou tal metodologia aos depósitos identificados no médio vale do Rio Doce. Meis \& Moura (1984) sugeriram que o conceito fosse restrito às condições nas quais fosse possível detectar, com base na estratigrafia, uma relação genética direta entre o depósito e a forma topográfica, devendo ser ainda considerado que o enfoque morfoestratigráfico subordina por demais a estratigrafia à percepção das formas de relevo (Moura \& Meis 1986).

De maneira geral, os depósitos quaternários, especialmente caracterizados por freqüentes similaridades litológicas, apresentam descontinuidades estratigráficas facilmente identificáveis, que representam importantes variações nos processos de sedimentação. Assim, podem ser melhor distingüidos, não por critérios relacionados ao conteúdo litológico, mas por descontinuidades limitantes.

A aloestratigrafia foi introduzida pelo Código Norte-Americano de Nomenclatura Estratigráfica (NACSN 1983), com o objetivo de identificar corpos estratiformes, mapeáveis, definidos com base em descontinuidades. Seu emprego foi inicialmente proposto para depósitos de idade neocenozóica, principalmente quaternários, distinguindo depósitos de litologia similar superpostos, contíguos ou separados geograficamente, ou distinguindo, como unidades únicas, depósitos caracterizados por heterpgeneidade lítica. Em todos os casos, é indispensável à definição que os corpos sejam delimitados por descontinuidades estratigráficas.

A aloestratigrafia, categoria material de classificação estratigráfíca (baseada em limites físicos), é adotada tentativamente neste trabalho, com a finalidade de estabelecer uma estratigrafia básica para os depósitos neoquatemários encontrados na região de Bananal $(\mathrm{SP} / \mathrm{RJ})$. $\mathrm{O}$ estudo realizado representa uma proposta fundamentada na necessidade de elaboração de colunas estratigráficas regionais, fornecendo a base indispensável à identificação e interpretação da seqüência evolutiva quaternária.

\section{CONSIDERAÇÕES SOBRE A ÁREA DE ESTUDO}

A região considerada situa-se no Planalto SE do Brasil, no sopé da Serra da Bocaina, dentro da área abrangida pelo médio vale do Rio Paraíba do Sul, englobando o município de Bananal (SP) e parte de municípios vizinhos, no limite entre $o s$ Estados de São Paulo e Rio de Janeiro (Fig. 1).

$\mathrm{Na}$ área, afloram rochas metamórficas do embasameito cristalino pré-cambriano, litologicamente diversas. Predominam gnaisses migmatíticos com estrutura bardada, ocorrendo intercalações menores de quartzitos, micaxistos, rochas calcio-silicáticas, anfibolitos e granulitos (Almeida et al. 1981). São comuns diques de rochas mesozóicas básicas e intermediárias. Tal embasamento, em virtude do predomínio de gnaisses, fornece um caráter bastante uniforme como área-fonte de sedimentos e na dinâmica evolutiva da paisagem. Em inconformidade, destaca-se um significativo pacote de sedimentos quaternários, subdivididos em diversas seqüências coluviais e aluviais.

As feições estruturais mais destacadas correspodem a falhas transcorrentes de idade pré-cambriana, concentradas em feixes com direção NE-SW, reativadas por movimentos verticais durante o Terciário. Encontram-se associadas a essas falhas, faixas miloníticas mais ou menos espessas. Baseados em feições dessa natureza, Hasui et al. (1978) enquadraram a região como parte do compartimento tectônico de Quebra-Cangalha, delimitado a SE pela falha de Taxaquara e a NW pela falha do Alto da Fartura. A região faz parte de uma depressão alongada

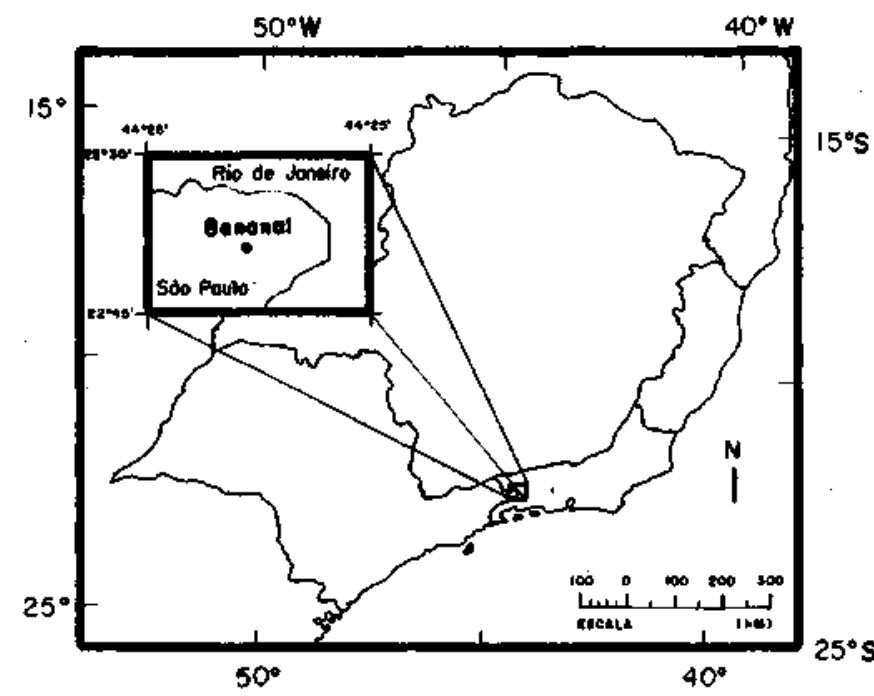

Figura 1 -Mapa com a localização da região de Bananal $(S P / R J)$

Figure 1 - Localization map of Bananal region (SP/RJ)

de origem tectônica, como foi identificado o médio vale do Rio Paraíba do Sul por Asmus \& Ferrari (1978).

Caracteriza o relevo da área a feição de colinas rebaixadas, mapeadas como "mar de morros" por Ponçano et al. (1981), predominando segmentos convexos, com os segmentos côncavos aparecendo nas baixas encostas e em cabeceiras de drenagem em anfiteatro. As feições estruturais consideradas funcionam como forte condicionante para o padrão de drenagem regional.

Condições paleo-hidrológicas e de nível de base mutáveis contribuíram para a evolução complexa da paisagem, originando as feições características do Planalto SE do Brasil (Meis \& Monteiro 1979) - fundos de depressão mal drenados, colinas isoladas, cabeceiras de drenagem em forma de alvéolos e vales apresentando depósitos registrados em mais de um nível de terraço fluvial.

O clima tropical da região é evidenciado por duas estações bem marcadas: verão chuvoso e inverno seco - regime este condicionado pela atuação das frentes frias que atingem o Sul e o Sudeste do Brasil. A temperatura média anual oscila em torno de $20^{\circ} \mathrm{C}$ e a pluviosidade média anual é da ordem de $1.500 \mathrm{~mm}$.

Estados realizados na região do médio vale do Rio Paraíba do Sul, abordando os depósitos quaternários, enfatizaram, de maneira geral, a estratigrafia dos materiais de encosta e a relação entre esses depósitos coluviais e a evolução das encostas (Moura \& Meis 1980, Meis et al 1981, Meis \& Moura 1984, Moura \& Meis 1986). Moura \& Meis (1986) elaboraram uma coluna estratigráfica preliminar para o Quaternário Superior na região de Bananal, na qual são reunidos sedimentos coluviais, aluviais e flúvio-lacustres, registrando, ainda, fases de pedogênese. A partir desse arcabouço estratigráfico, os autores procuraram mostrar as relações entre a litoestratigraf ia, aloestratigrafia, e da foestratigrafia e morfoestratigrafia nos depósitos neoquaternários da região, fornecendo, também, uma proposta de classificação aloestratigráfica informal para os depósitos coluviais estudados.

As seqüências sedimentares encontradas evidenciam descontinuidades morfológicas e estratigráficas que parecem estar relacionadas a eventos evolutivos diferenciados, cujo entendimento necessita de caracterização detalhada dos depósitos neoquatemários.

PROCEDIMENTOS UTILIZADOS PARA A DEFINIÇÃO DAS UNIDADES PROPOSTAS A proposição 
formal das unidades aloestratigráficas definidas segue os procedimentos recomendados pelo Código Norte-Americano de Nomenclatura Estratigráfica (NACSN 1983) e, apesar de a aloestratigrafia não estar relacionada no recente Código Brasileiro de Nomenclatura Estratígráfíca (CENE/SBG 1986), foram consideradas as regras gerais contidas no Guia de Nomenclatura para o estabelecimento de unidades estratigráficas formais.

A definição das unidades, pela identificação de descontinuidades estratigráficas nas seqüências deposicionais consideradas, baseou-se na existência de um arcabouço estratigráfico preliminar (Moura \& Meis 1986); argumentos sedimentológicos e morfológicos contribuíram para a escolha dos limites. Nos depósitos fluviais, são identificadas descontinuidades erosivas nítidas, ressaltadas ou não por variações litológicas, sendo a principal delas associada à diferenciação entre os níveis de terraços fluviais. Quanto aos depósitos coluviais, a distinção é evidenciada a partir de levantamentos estratigráficos detalhados, sendo auxiliada pela presença de feições pedogenéticas (paleo-horizontes A) ou por linhas de seixos.

Relações geomorfológicas controlam a distribuição dos depósitos identificados e, nesse sentido, foram efetuados mapeamentos das feições morfológicas, com o uso de fotografias aéreas na escala 1:25.000 (Terrafoto) e mapas topográficos nas escalas 1:25.000 (Ministério do Exército) e 1:10.000 (Estado de São Paulo), como suporte para o reconhecimento das seqüências sedimentares a serem estudadas.

O estudo detalhado das seqüências deposicionais foi efetuado pelo levantamento sistemático de paredes expostas, adotando-se a técnica descrita por Paepe (in Moura \& Meis 1986): definição, com o auxílio de um nível, de uma Unha horizontal que serve como referência para o desenho da parede exposta, pelo acompanhamento de descontinuidades sedimentológicas e morfológicas. Foram também realizadas sondagens em áreas selecionadas, com o objetivo de considerar o comportamento tridimensional das unidades deposicionais, especialmente os depósitos de encosta. Na escolha das secões de referência, foi documentada a representatividade espacial das seqüências deposicionais neoquatemárias preservadas na área de estudo (Fig. 2)

Identificadas as unidades aloestratigráficas, foi feita coleta sistemática de amostras, visando a caracterização sedimentológica dos materiais, subdividida em análises texturais e mineralógicas (minerais leves e pecados). Os resultados obtidos, embora não decisivos à definição, forneceram elementos significativos à descrição das unidades.

A utilização do enfoque aloestratigráfico possibilita que os estudos detalhados exigidos para o entendimento da sedimentação quaternária tenham a base estratigrafica indispensável. A mapeabilidade das unidades definidas foi testada em diversas escalas, muitas vezes sendo necessário recorrer ao mapeamento por associação de unidades para ser possível representar unidades subsuperficiais de grande significado na seqüência evolutiva, ficou evidenciado que não deve existir uma escala padrão de mapeamento; na verdade, o controle da sedimentação neoquatemária está ligado a unidades geodinâmicas de evolução (cabeceiras de drenagem em anfiteatro) que, por sua vez, ocorrem em escalas variadas, repercutindo na diversidade de escalas de trabalho.

O reconhecimento e a extensão das unidades aloestratigráficas definidas, a partir das áreas-tipo, foram realizados por meio da correlação das descontinuidades que as delimitam, da comparação de suas características sedimentológicas e da observação de suas relações com as feições geomorfológicas associadas.

CLASSIFICAÇÃO ALOESTRATIGRÁFICA PROPOSTA $O$ registro sedimentar neoquaternário identificado na região de Bananal $(\mathrm{SP} / \mathrm{RJ})$, ordenado com base em suas relações aloestratigráficas (Fig. 3), evidencia freqüentes inter- calações entre depósitos de encosta e fluviais. As unidades aloestratigráficas propostas representam seqüências sedimentares reconhecidas regionalmente.

Aloformação Santa Vitória Os mais antigos testemunhos da sedimentação quaternária reconhecidos regionalmente correspondem a depósitos coluviais, reunidos sob a denominação Aloformação Santa Vitória, nome proveniente de um curso fluvial em cuja bacia de drenagem localiza-se a seção-tipo proposta para a unidade: Seção Treviso (Fig. 4a).

São indicadas como seções de referência suplementares as seç̃es Bom Retiro (Fig. 5a), Fazendinha (Fig. 6b), Três Barras (Fig. 6c) e Rialto/Tl (Fig. 8a).

A Aloformação Santa Vitória é caracterizada por uma seqüência de colúvios avermelhados, mapeáveis exclusivamente em subsuperfícies, encontrados, em geral, em inconformidade com o embasamento cristalino muito alterado, algumas vezes delineado por linhas de seixos, estando preservados em interflúvios ou encostas laterais (side slopes) de anfiteatros. Estas relações podem ser melhor visualizadas pela análise das sondagens efetuadas: Treviso (Fig. 4b), Bom Retiro (Fig. 5b) e Bela Vista (Fig. Tb)

Regionalmente, os depósitos dessa unidade são identificados como seqüência coluvial subdividida em duas camadas descontínuas: a camada inferior é representada por materiais silto-argilosos, de coloração avermelhada, com freqüentes grânulos de quartzo; a camada superior é composta por materiais areno-argilosos, avermelhados, com granules de quartzo. Esses depósitos são maciços, extremamente mal selecionados, e apresentam estrutura pedogenética prismática característica. Para as duas camadas que compõem a unidade Santa Vitória foram adotadas as denominações informais Treviso I e Treviso $\mathrm{H}$, respectivamente, propostas por Moura \& Meis (1986). No total, apresentam espessuras variáveis, existindo registros identificados da ordem de até $6 \mathrm{~m}$. Pela ausência de melhores argumentos para os processos de alteração, geológicos e/ou pedogenéticos, somada à pequena expressão estratigráfica da unidade, considera-se prematura sua subdivisão em duas aloformações.

A Áloformação Santa Vitória parece corresponder a depósitos coluviais resultantes do retrabalhamento direto do embasamento cristalino alterado, ao qual a camada inferior assemelha-se bastante. A camada superior apresenta indícios de forte pedogênese ferralítica. $\mathrm{O}$ fato de esses depósitos estarem associados a feições geomorfológicas quaternárias (rampas de colúvio), estratigraficamente abaixo de uma seqüência coluvial cujo solo nela desenvolvido data de aproximadamente 10.000 anos, sugere idade pleistocênica para a Aloformação Santa Vitória.

Aloformação Rio do Bananal Situada em discordância erosiva sobre os depósitos da unidade Santa Vitória, encontra-se uma seqüência coluvial cuja denominação Aloformação Rio do Bananal é derivada do principal curso fluvial que corta a região, afluente direto do Rio Paraíba do Sul, e proposta em virtude da grande representatividade documentada para os depósitos dessa unidade.

Como estratótipo da unidade Rio do Bananal, é indicada a Seção Bom Retiro (Fig. 5a), sendo utilizadas como suplementares as seções Treviso (Fig. 4a), Fazendinha (Fig. 6b), Ires Barras (Fig. 6c), Cerâmica Joana D'Arc/Tl (Fig. 8b) e Córrego do Resgate HI (Fig. 10c).

Os depósitos da unidade Rio do Bananal, mapeados normalmente apenas em subsuperfície, exceto em condições de alteração recente da paisagem, natural ou artificial, representam uma espessa seqüência (espessuras variáveis, podendo ser superiores a $8 \mathrm{~m}$ ) constituída por materiais argilo-arenosos, amarelados, com freqüentes granules de quartzo, denominada informalmente colúvio Bom Retiro (Moura \& Meis 1986). Apresentam-se maciços, extremamente mal selecionados, 


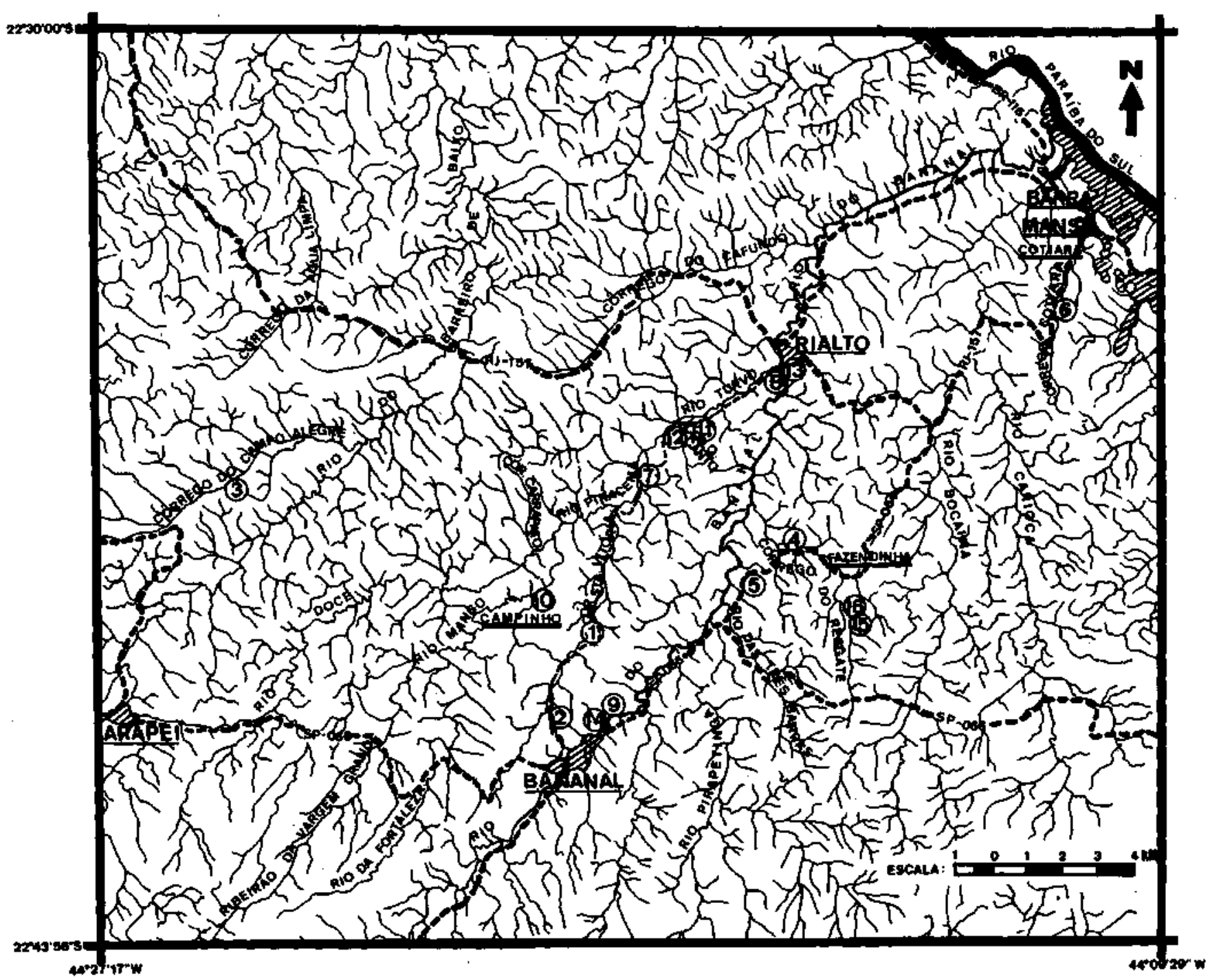

LEGENDA

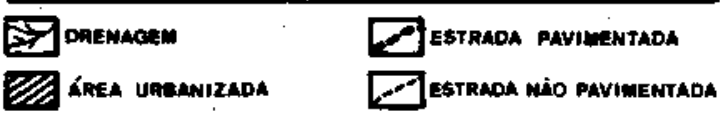

Figura 2 - Mapa de localização das seções estratigráficas de referência às unidades definidas: 1. Seção Treviso/Sondagem Treviso; 2. Seção Bom Retiro/Sondagem Bom Retiro; 3. Seção Campo Alegre; 4. Seção Fazendinha; 5. Seção Três Barras; 6. Seção Cotiara; 7. Seção Bela Vista; 8. Seção Rialto/T1; 9. Seção Cerâmica Joana D'Arc/T1; 10. Seção Campinho; 11. Seção Turvo; 12. Seção Piracema; 13. Seção Rialío/T2; 14. Seção Cerâmica Joana D'Arc/T1; 15. Seção Córrego do Resgate III; 16. Seção Córrego do Resgate IV

Figure 2 - Localization map of reference stratigraphic sections: 1. Treviso Section/Treviso Drillhole; 2. Bom Retiro Section/Bom Retire Drillhole; 3. Campo Alegre Section; 4. Fazendinha Section; 5. Três Barras Section; 6. Cotiara Section; 7. Bela Vista Section; 8. Rialto/Tl Section; 9. Cerâmica Joana D'Arc/Tl Section; 10. Campinho Section; 11. Turvo Section; 12. Piracema Section; 13. Rialto/T2 Section; 14 Cerâmica Joana D'Arc/T2 Section; 15. Córrego do Resgate HI Section; 16. Córrego do Resgate TV Section

com estrutura pedológica em blocos, sendo comum o mosqueamento por óxidos de ferro.

O limite superior da Aloformação Rio do Bananal é freqüentemente marcado por uma feição pedogenética (paleohorizonte A) com significado estratigráfico regional, apresentando fragmentos vegetais carbonizados datados em 9.800 anos, o que leva os depósitos dessa unidade a serem atribuídos à idade pleistocênica, próximo ao limite Pleistoceno/Holoceno.

A seqüência coluvial que constitui a Aloformação Rio do Bananal parece representar uma fase de intensa atividade na dinâmica das encostas, produzindo um espesso pacote coluvial que preencheu as reentrâncias dos anfiteatros (hollows), como pode ser documentado nas sondagens Bom Retiro (Fig. 5b) e Bela Vista (Fig. Tb), prolongando-se, localmente, sob forma de rampa suavemente inclinada, até o fundo dos vales fluviais, onde pode ser reconhecido na base do terraço fluvial superior (TI).

Aloformação Rio das Três Barras Os primeiros registros de sedimentação no domínio dos cursos fluviais, identificados regionalmente, correspondem a depósitos argilosos englobados sob a denominação Aloformação Rio das Três Barras, nome retirado de um curso fluvial afluente do Rio do Bananal, situado próximo à seção-tipo escolhida para representar a unidade - Seção Cerâmica Joana D'Arc/Tl (Fig. 8b), 


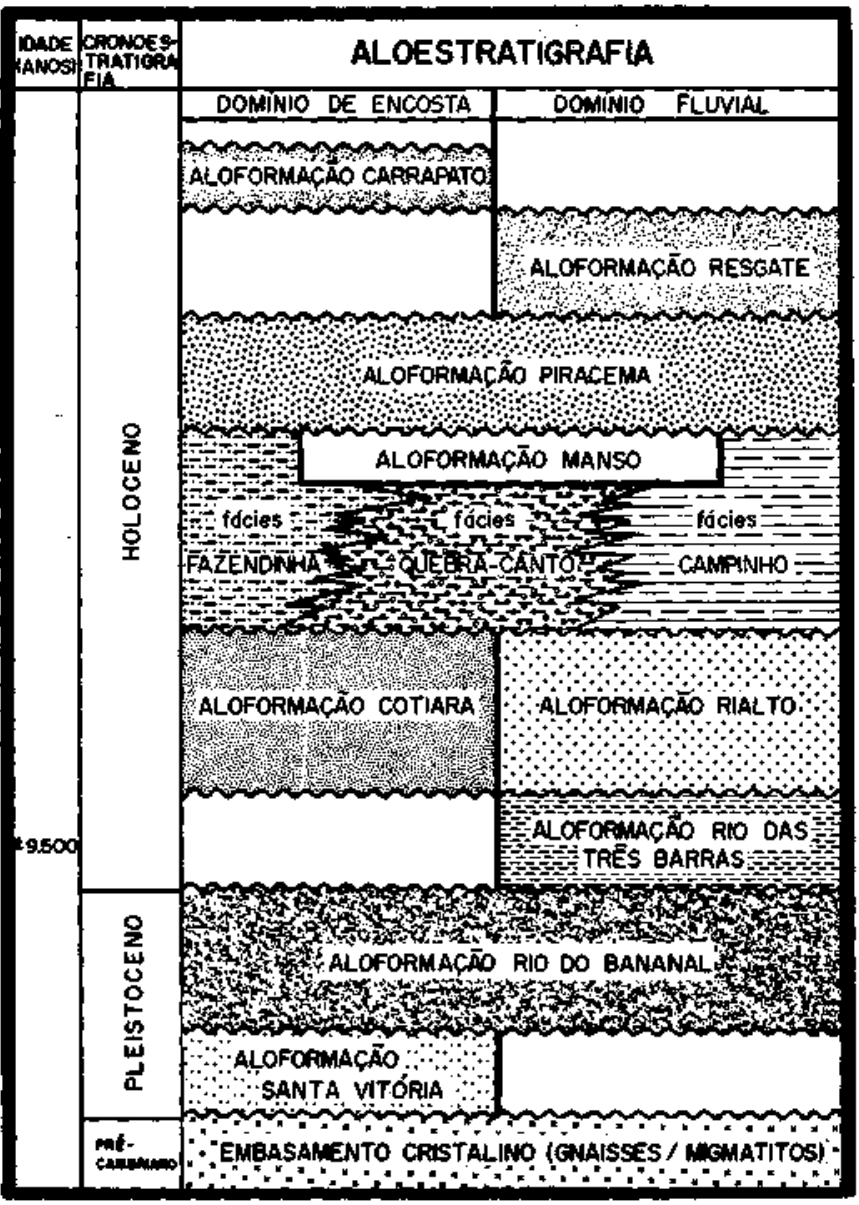

Figura 3 - Coluna aloestratigráfica elaborada para o Quaternário superior da região de Bananal (SP/RJ). A subdivisão em domínios de encosta e fluvial representa os compartimentos geomorfológicos em que os depósitos são encontrados, não indicando, necessariamente, sua gênese Figure 3 - Upper Quaternary allostratigrafic column for Bananal region (SP/RJ). Hillslope and fluvial domains represent geomorphological compartments where the deposits are found. The genesis of the sedimentary units is not necessarily related to these domains

na qual as feições principais da unidade podem ser reconhecidas. São indicadas como seções suplementares à descrição as seções Campinho (Fig. 9a), Córrego do Resgate Dl (Fig. 10c) e Córrego do Resgate IV (Fig. 10d).

Os depósitos da unidade Rio das Três Barras podem ser registrados somente em mapeamentos de subsuperfície, ocorrendo descontinuamente na base dos terraços fluviais, em freqüente discordância sobre a unidade Rio do Bananal.

Esses depósitos correspondem a uma seqüência argilosa que pode ser subdividida em duas camadas superpostas: a camada inferior é representada por argila cinza-escuro, apresenta laminações horizontais milimétricas e preserva matéria orgânica em grande quantidade (troncos e restos vegetais em geral); a camada superior constitui-se de material argiloso, rosado, também apresenta laminações horizontais milimétricas, com finos níveis de areia de granulometria fina interacamados, indícios de bipturbação e restos vegetais. As duas camadas são caracteristicamente micáceas, sendo verificada a passagem gradacional entre elas. São estimadas espessuras de até $3 \mathrm{~m}$, mas possivelmente alcançam valores maiores.

Datações realizadas em troncos vegetais carbonizados, colhidos na camada inferior, registraram a idade de $9.545 \pm 75$ anos (Moura \& Meis 1986). Estudos palinológicos preliminarmente desenvolvidos indicam índices de humificação atribuíveis a ambientes lacustres e associações de tipos polínicos que caracterizam a transição de condições secas para úmidas (Pessoa 1987).

A gênese sugerida para os depósitos da unidade Rio das Três Barras parece estar ligada a paleolagos holocênicos resultantes de represamentos locais dos cursos fluviais pela elevação de níveis de bases locais, associados ao entulhamento dos fundos de vale pelos depósitos de encosta que compõem a aloformação Rio do Bananal. Reforça essa hipótese o caráter descontínuo dos depósitos e a presença freqüente da Aloformação Rio do Bananal na base dos terraços fluviais, além das características sedimentológicas apresentadas pelos depósitos argilosos, distinguindo-os como argilas de origem flúvio-lacustre.

Aloformação Cotiara A denominação Aloformação Cotiara é proposta para uma seqüência coluvial identificada em discordância erosiva sobre os depósitos da Aloformação Rio do Bananal, tendo seu nome derivado de um curso fluvial em cuja bacia de drenagem está localizada a seção-tipo indicada para a unidade - Seção Cotiara (Fig. 7a).

São indicadas, como seções de referência suplementar à definição da unidade, as seções Treviso (Fig. 4a), Bom Retiro (Fig. 5a), Fazendinha (Fig. 6b), Três Barras (Fig. 6c) e Piracema (Fig. 9c).

Os depósitos da unidade Cotiara caracterizam-se como materiais argilo-arenosos a areno-argilosos, amarelados, com freqüentes granules de quartzo, extremamente mal selecionados, maciços, mas bastante friáveis, apresentando estrutura pedológica granular e podendo preservar localmente o paleonorizonte A. São registradas espessuras da ordem de até $8 \mathrm{~m}$, mas existem evidências de que possam atingir espessuras maiores. Esses depósitos, definidos informalmente por Moura \& Meis (1986) como colúvio Campo Alegre, são litologicamente bastante similares àqueles que constituem a Aloformação Rio do Bananal.

Ao contrário das unidades subjacentes, os depósitos da unidade Cotiara podem ser mapeados em superfície e subsuperfície. Ocorrem em situações particulares: freqüentemente são encontrados em posição de interflúvio, documentando inversões na topografia das encostes e preenchendo reentrâncias (hollows) suaves de anfiteatros. Essas relações podem ser observadas nas sondagens Dom Retiro (Fig. 5b) e Bela Viste (Fig. Tb), assim como nos mapeamentos efetuados (Figs, li a 14). Os depósitos da unidade Cotiara podem ser facilmente reconhecidos por meio desses critérios morfológicos.

A Aloformação Cotiara parece representar retrabalhamento da unidade Rio do Bananal, documentado pelas relações texturais, que apresentam decréscimo na fração de finos, e pelas relações mineralógicas, bastante semelhantes. É encontrada somente no domínio das encostas, não tendo sido registradas relações de contato direto com os depósitos fluviais; relações estratigráfícas indiretas sugerem ser a seqüência coluvial representada pela Aloformação Cotiara posterior à deposição das argilas da unidade Rio das Três Barras.

Aloformação Rialto A denominação Aloformação Rialto é proposta para a uma seqüência arenosa com significativa expressão regional que, em muitos locais, forma o arcabouço sedimentar básico do nível superior de terraço fluvial (T1). O nome é retirado da cidade de Rialto, distrito de Barra Mansa (RJ), nas proximidades da qual situa-se a seçãotipo proposta para representar a unidade: Seção Rialto/Tl (Fig. 8a).

As seções Cerâmica Joana D'Arc/Tl (Fig. 8b) e Córrego do Resgate III (Fig. 10c) são indicadas como seções de referência suplementares à descrição da unidade.

Os depósitos da unidade Rialto, normalmente mapeáveis apenas em subsuperfície, são encontrados em discordância erosiva sobre as argilas da unidade Rio das Três Barras ou, menos freqüentemente, em discordância erosiva sobre os de- 


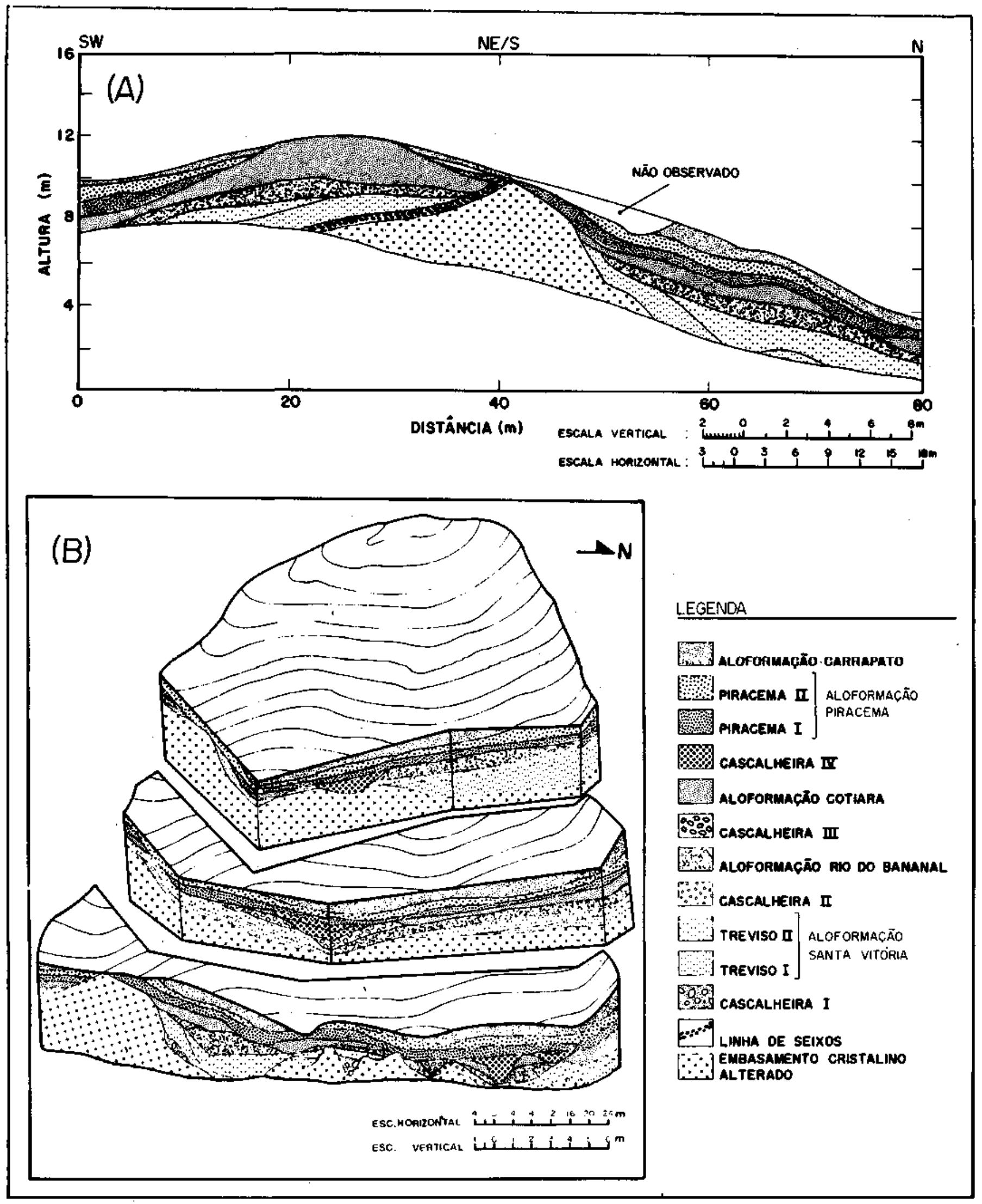

Figura 4 -A. Seção Treviso; B. Re constituição tridimensional do comportamento em subsuperficie das unidades aloestratigráficas no anfiteatro Treviso; localizadas na estrada Bananal (SP) - Rialto (RJ), a 4,5 km da cidade de Bananal, à esquerda do córrego Santa Vitória

Figure 4 - A. Tieviso Section; B. Threedimensional reconstruction of allostratigraphic units in Treviso amphitheater. Bananal (SP) - Rialto (RJ) road, $4.5 \mathrm{~km}$ from Bananal city, on the left margin of Santa Vitória creek 

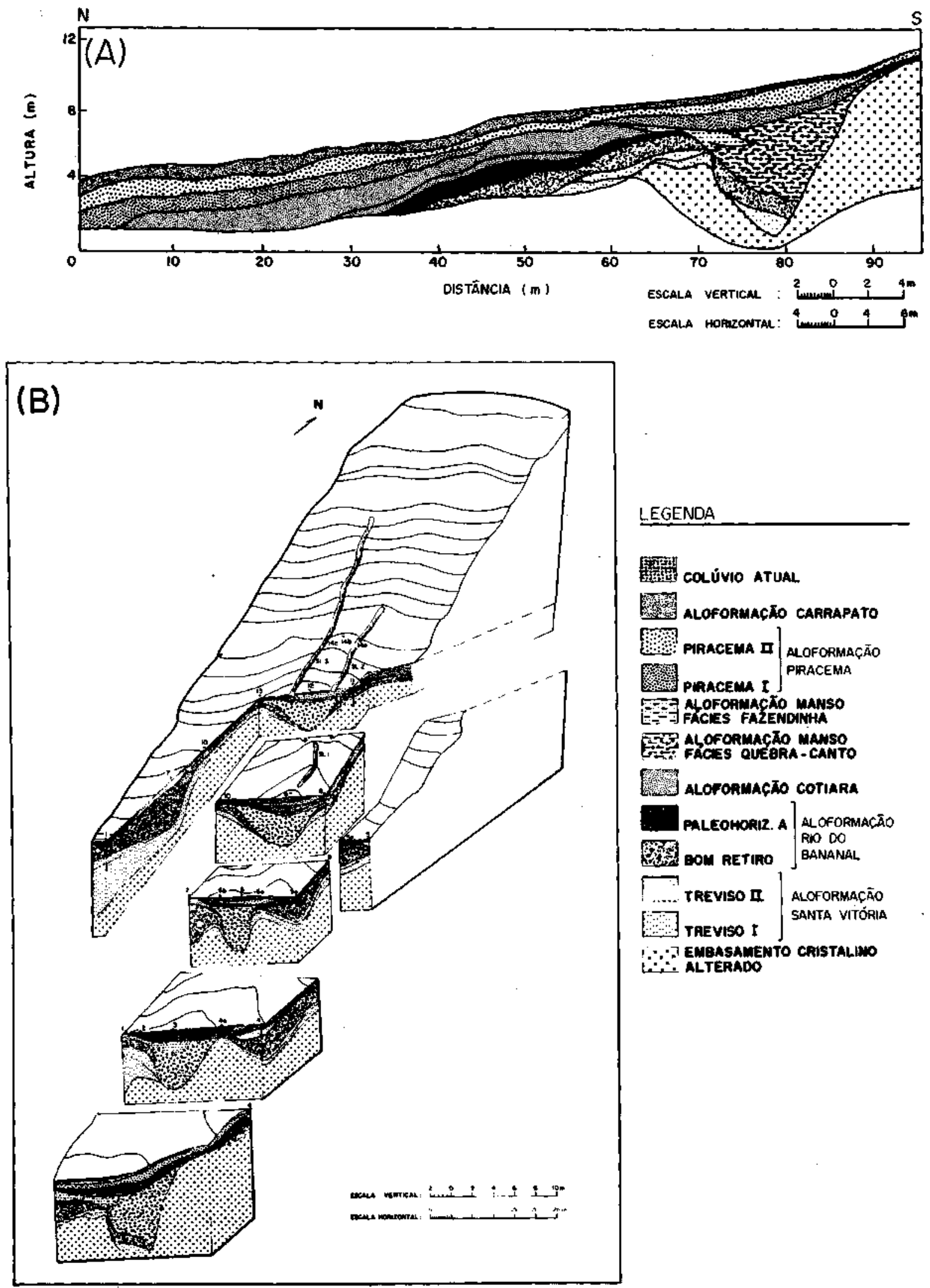

Figura 5 -A. Seção Bom Retiro (modificada de Moura \& Meis 1986); B. Reconstituição tridimensional do comportamento em subsuperficie das unidades aloestratigráficas no anfiteatro Bom Retiro; localizadas na estrada Bananal (SP) - Rialto (RJ), a 1,5 km da cidade de Bananal, à direita do córrego São João

Figure 5 - A. Bom Retiro Section (modified from Moura \& Meis 1986); B. Threedimensional reconstruction of allostratigraphic units in Bom Retiro amphitheater. Bananal (SP) - Rialto (RJ) road, $1.5 \mathrm{~km}$ from Bananal city, on the right margin of São João creek 

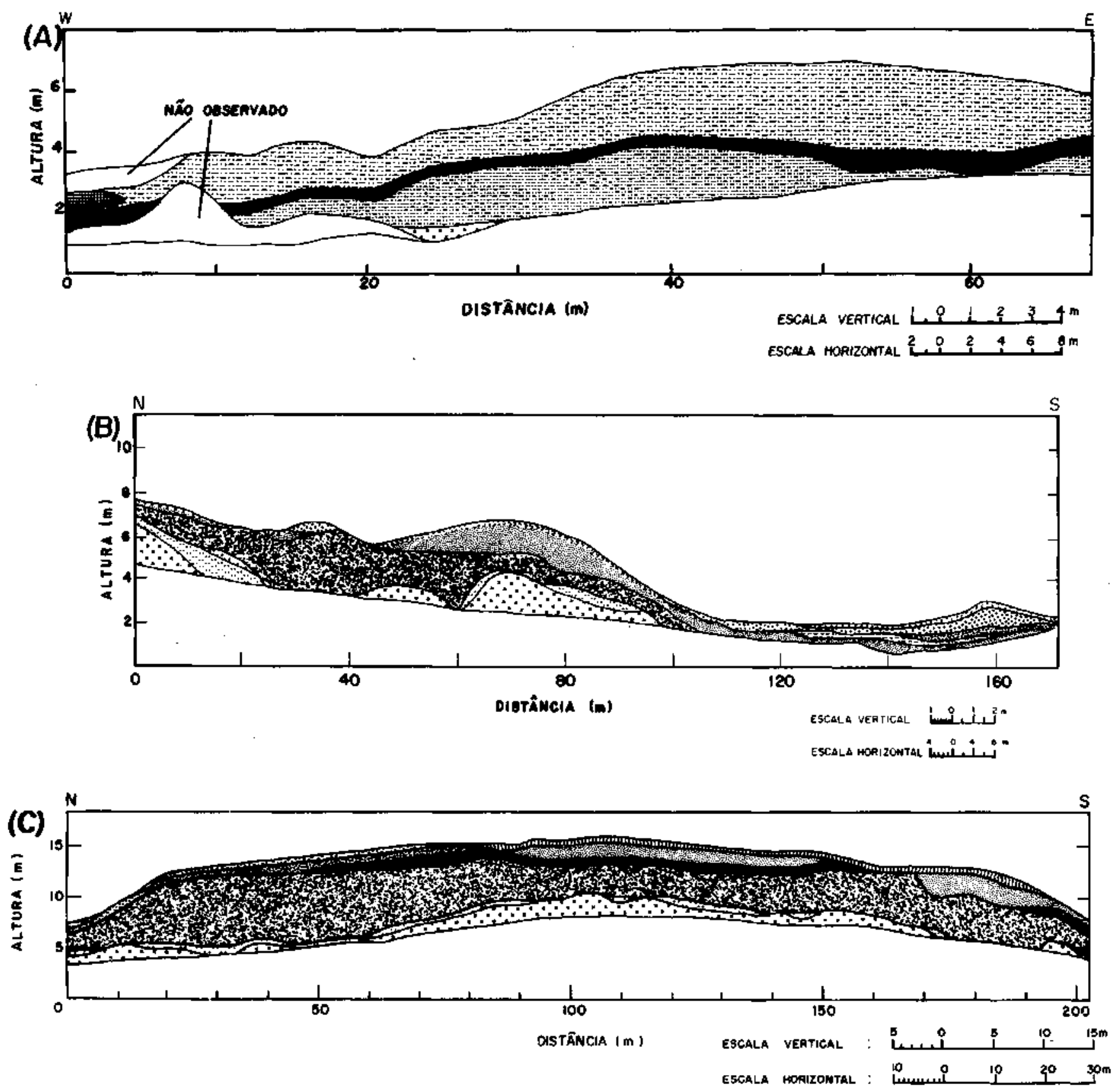

LEGENDA

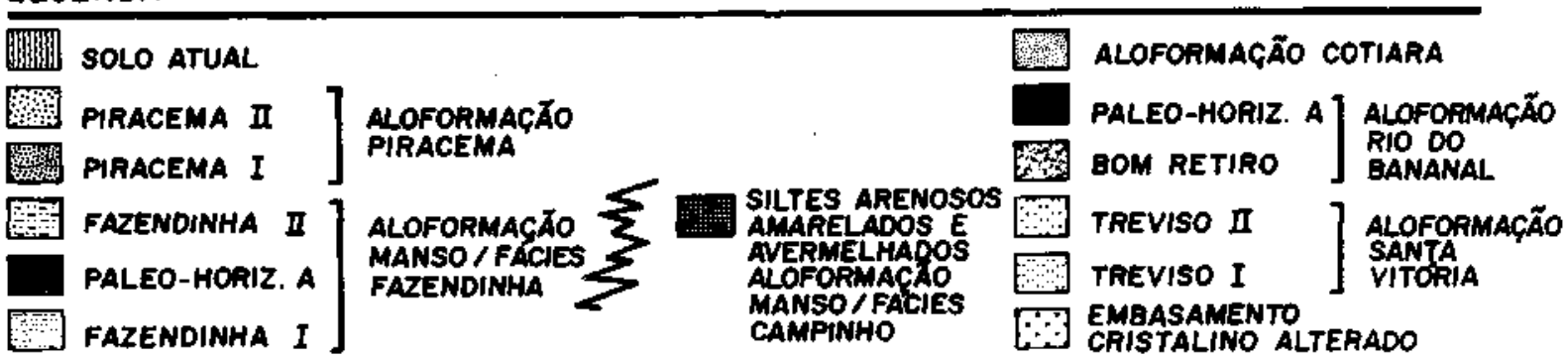

Figura 6-A. Seção Campo Alegre (modificada de Moura \& Meis 1986), localizada a 2 km a partir da SP-066, em uma estrada que acompanha o córrego do Campo Alegre, a $8 \mathrm{~km}$ da cidade de Arapeí (SP); B. Seção Fazendinha, localizada na SP-064, a $9 \mathrm{~km}$ da cidade de Bananal (SP), em frente à sede da Fazenda do Resgate; C. Seção Três Barras, localizada na SP-064, a 6,5 km da cidade de Bananal (SP)

Figure 6 - A. Campo Alegre Section (modified from Moura \& Meis 1986), situated $2 \mathrm{~km}$ from SP-066 through a road that follows Campo Alegre creek,

8 km from Arapeí city; B. Fazendinha Section, SP-064, 9 km from Bananal city, in front of Resgate Farm seat; C. Três Barras Section, SP-064, 6.5 km from Bananal city 

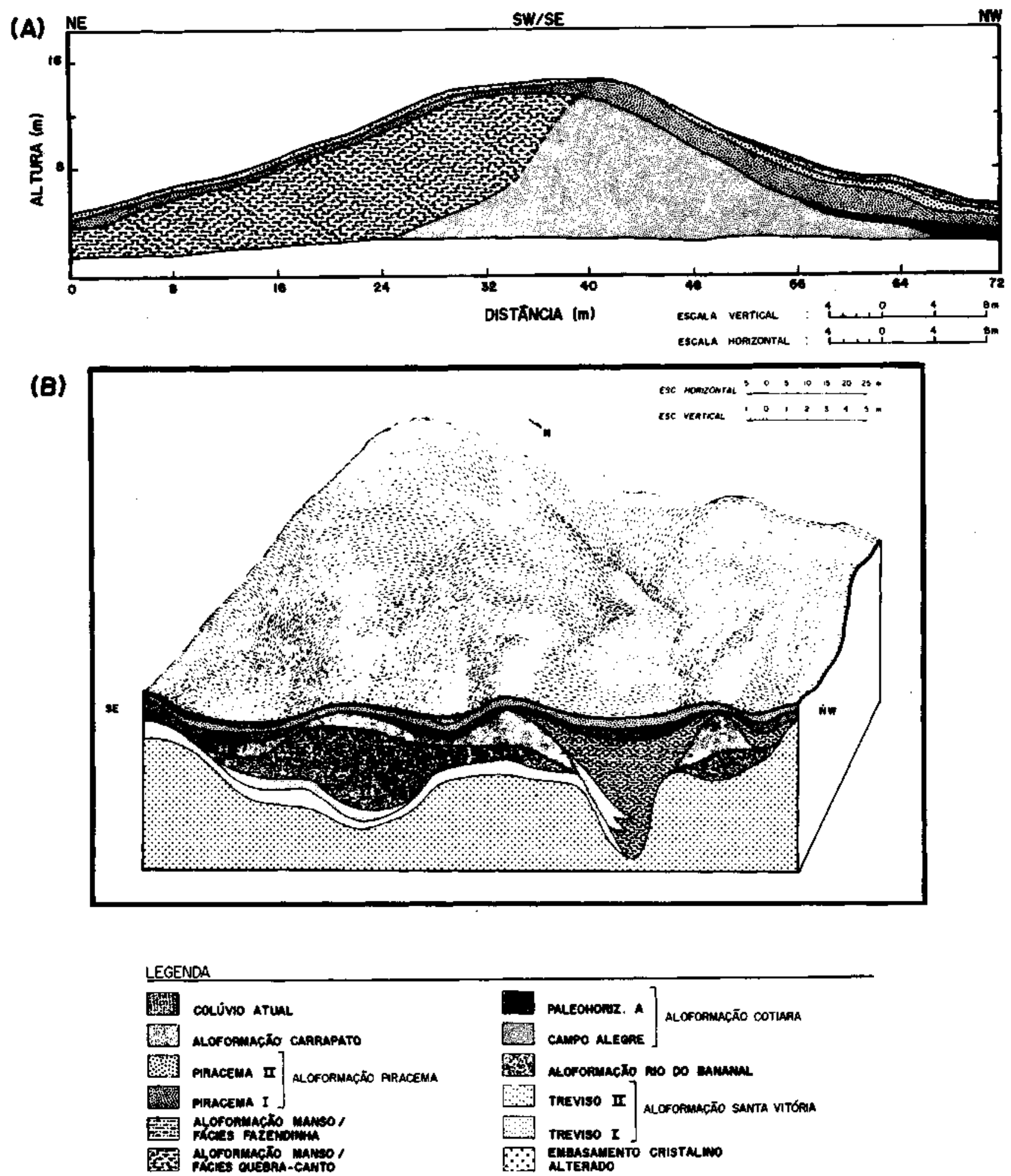

Figura 7-A. Seção Cotiara, situada na localidade conhecida como Km-4, Cotiara (distrito de Barra Mansa, RJ), a aproximadamente $750 \mathrm{~m}$ a partir da RJ-157; B. Seção Bela Vista, reconstituição do comportamento em subsuperficie das unidades aloestratigráficas, localizada na estrada Bananal (SP) - Rialto (RJ), a $13 \mathrm{~km}$ de Bananal (voçoroca da Fazenda Bela Vista) Figure 7 - A. Cotiara km-4 locality, Cotiara (Barra Mansa subdistrict RJ), 750 m from RJ-157; B. Bela Vista Section, undersurface arrangement of allostratigraphic units, Bananal (SP) - Rialto (RJ) road, $13 \mathrm{~km}$ from Bananal

pósitos das unidades Rio do Bananal ou Santa Vitória, podendo ainda ser identificados em inconformidade com o embasamento cristalino alterado. Parecem ser contemporâneos aos depósitos da unidade Cotiara, mas associados a ambientes distintos, não havendo relação de contato direto registrada.

A Aloformação Rialto é representada por uma seqüência predominantemente arenosa, onde podem ser reconhecidas três camadas principais. A camada inferior é caracterizada por areias médias a grossas, mal selecionadas, de cores variadas, esbranquiçadas, amareladas, avermelhadas, com freqüentes níveis de oxidação, apresentando estratificações cruzadas de médio porte, planares e acanaladas, com estratos bem desenvolvidos e níveis de cascalho fino. Cpmposicionalmente, são bastante quartzosas, algo feldspáticas, micá- 

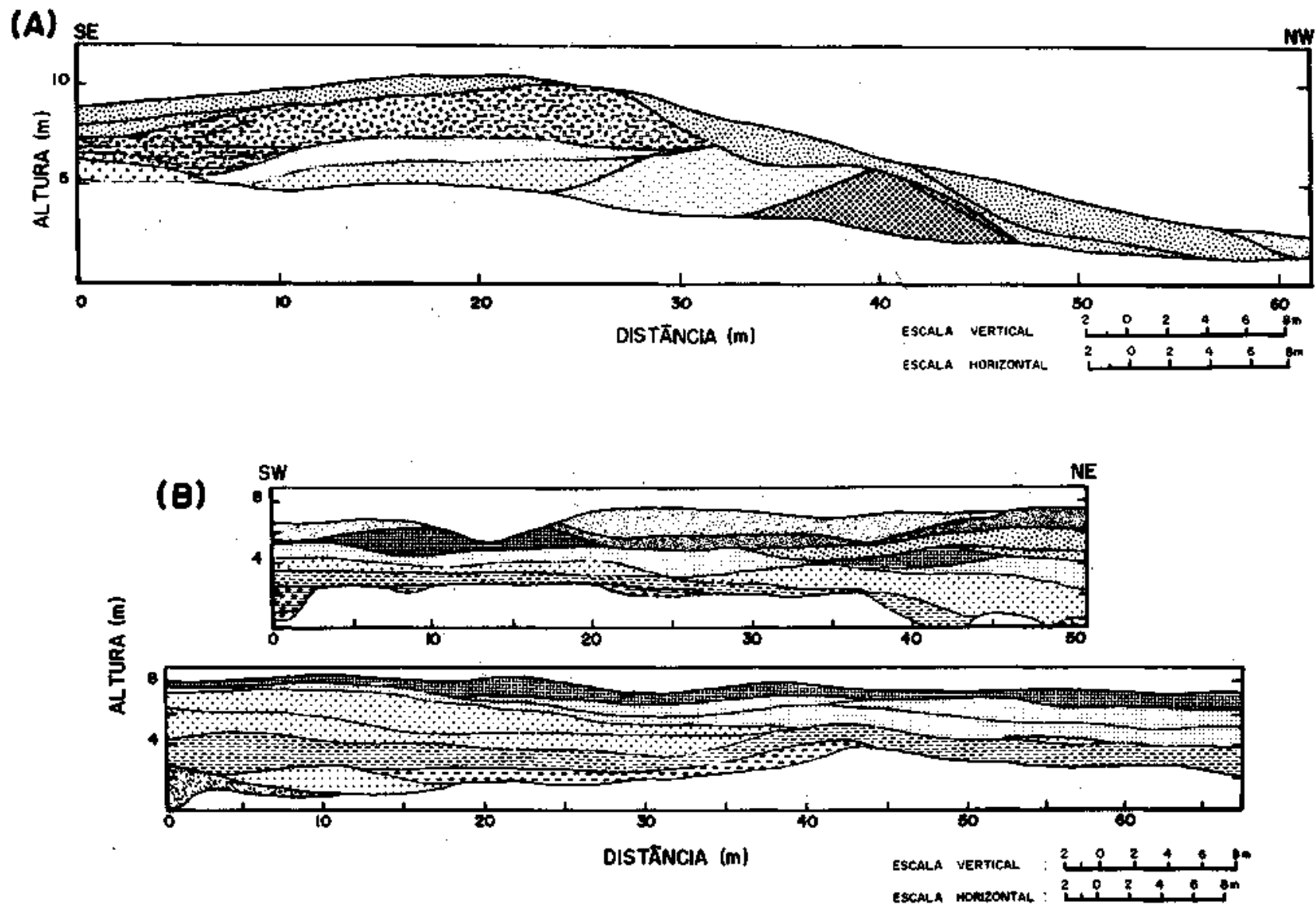

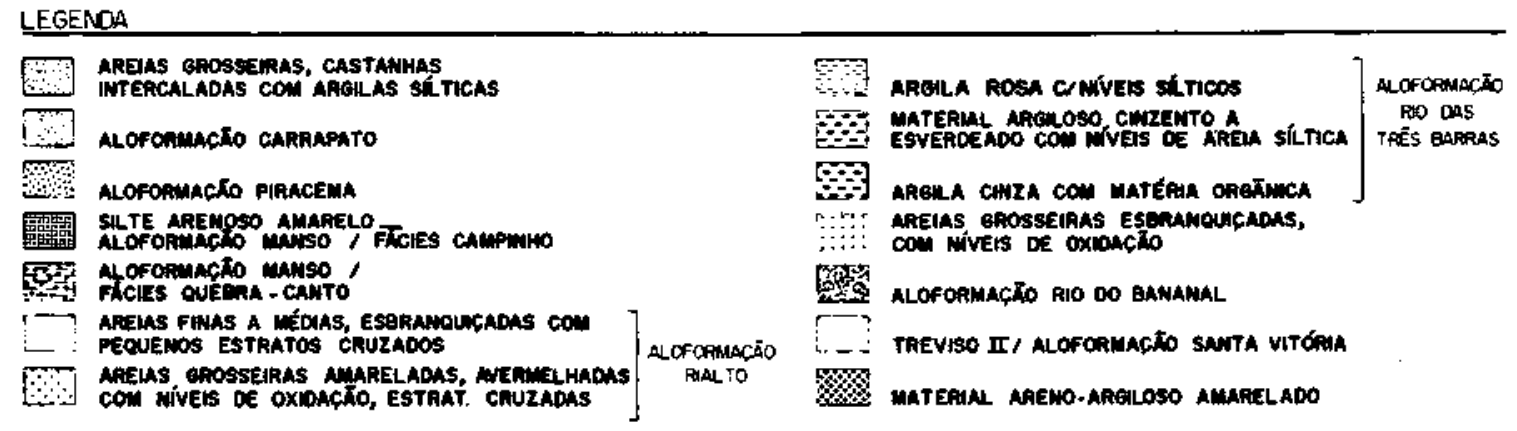

Figura 8-A. Seção Rialto/T1, localizada na estrada Bananal (SP) - Rialto (RJ), a 17,5 km de Bananal; B. Seção Cerâmica Joana D'Arc/T1 (modificada de Moura \& Meis 1986), localizada na SP-066, a 1,5 km da cidade de Bananal (SP), no terreno pertencente à antiga cerâmica Joana D 'Arc, à margem esquerda do Rio do Bananal

Figure 8 - A. Rialto/Tl Section, Bananal (SP) - Rialto (RJ) road, $17.5 \mathrm{~km}$ from Bananal; B. Cerâmica Joana D'Arc/Tl Section (modified from Moura \& Meis 1986), SP-066, $1.5 \mathrm{~km}$ from Bananal city, on the left margin of Bananal river

ceas. Uma camada intermediária caracteriza-se pela interdigitação de lentes arenosas, silticas e cascalhos; predominam areias de gramilometria média a grossa, amareladas, com estratificações cruzadas bem desenvolvidas, quartzosas, micáceas, feldspátícas; lentes de areia síltica interacamadas, de coloração cinza, rosada ou amarelada, sem estrutura visível, micáceas, podendo ou não preservar matéria orgânica; lentes de cascalhos arenosos, com matriz de areia média a grossa, apresentando seixos subangulosos a subarredondados de quartzo e fragmentos de rocha, e estratíficações cruzadas pouco visíveis. A camada superior apresenta areias finas a médias, mal selecionadas, eshranquiçadas a acastanhadas, com estratificações cruzadas planares de pequeno porte; essencialmente quartzosas e micáceas.
Na sua totalidade, os, depósitos da Aloformação Rialto apresentam espessuras registradas de até $5 \mathrm{~m}$, havendo evidências de espessuras maiores.

A gênese das areias da unidade Rialto parece estar relacionada a ambiente fluvial do tipo braided, apresentando fácies que parecem ajustar-se àquelas sugeridas por Miall (1977). Existem, de fato, variações sedimentológicas que precisam de análise mais detalhada sobre a caracterização dos subambientes fluviais responsáveis pela sedimentação das diversas camadas.

Aloformação Manso Sob a denominação Aloformação Manso são reunidos depósitos caracterizados por uma extrema heterogeneidade lítica, em nítida discordância erosiva 


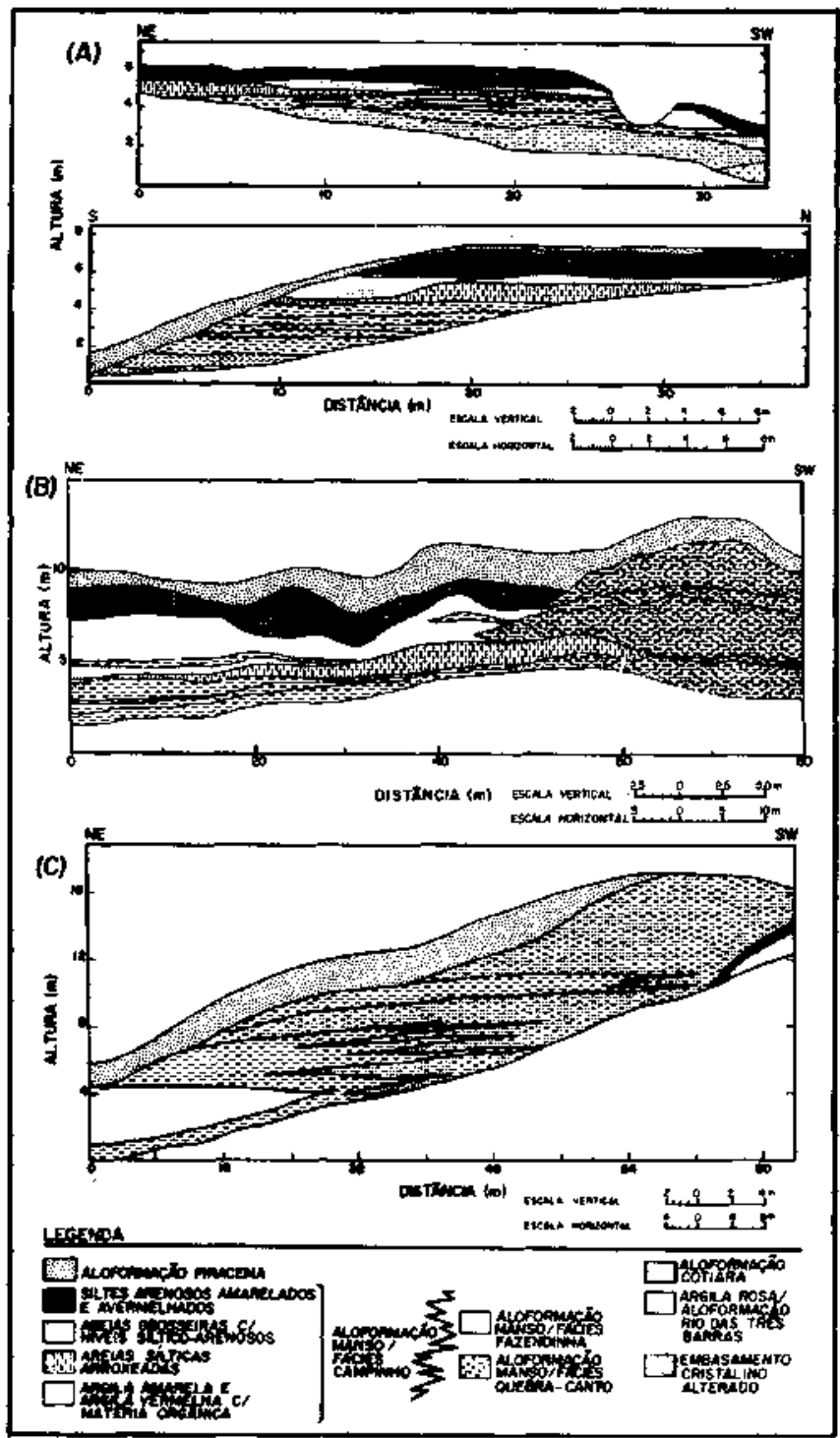

Figura 9- A. Seção Campiriho (modificada de Moura \& Meis 1986), situada na localidade conhecida como Campinho, a $5,5 \mathrm{~km}$ de Bananal (SP), próxima à confluência do córrego São João com o Rio Manso; B. Seção Turvo, localizada na estrada Bananal (SP) - Rialto (RJ), a $15 \mathrm{~km}$ da cidade paulista. C. Seção Piracema, localizada na estrada Bananal (SP) Rialto (RJ), a $14,5 \mathrm{~km}$ da cidade paulista, próxima ao gasoduto da Petrobrás (GASPAL)

Figure 9 - A. Campinho Section (modified from Moura \& Meis 1986), situated at Campinho, S.S km from Bananal, near the confluence between São João creek and Manso river; B. Turvo Section, Bananal (SP) - Rialto (RJ) road, $15 \mathrm{~km}$ from Bananal; C. Piracema Section; Bananal (SP) - Rialto (RJ) road, $14.5 \mathrm{~km}$ from Bananal

sobre as unidades subjacentes, podendo mesmo ser encontrados em inconformidade com o embasamento cristalino alterado. São depósitos de expressivo significado estratigráfico na região considerada, tendo sido a designação Manso proveniente de um curso fluvial de grande porte na área de estudo. Variações sedimentológicas e relações estratigráficas variadas tornam necessário, para que os depósitos da unidade Manso possam ser melhor representados, o estabelecimento de um estratótipo composto. Assim, foram escolhidas como principais as seções Turvo (Fig.9b) e Piracema (Fig. 9c); como suplementares, as seções Bom Retiro (Fig. 5a), Campo Alegre
(Fig. 6a), Fazendinha (Fig. 6b), Três Barras (Fig. 6c), Cotiara (Fig. 7a), Rialto/Tl (Fig. 8a), Cerâmica Joana D'Arc/Tl (Fig. 8b), Campinho (Fig. 9a), Córrego do Resgate III (Fig. 10c) e Córrego do Resgate IV (Fig. 10d).

A Aloformação Manso engloba uma seqüência sedimentar constituída por depósitos de encosta e fluviais intimamente interdigitados, sendo reconhecidas três associações de fácies sedimentares principais, informalmente denominadas como fácies Campinho, fácies Quebra-Canto e fácies Fazendinha, distinguíveis em superfície e subsuperfície. Essa subdivisão tornou-se necessária pois, ao individualizar depósitos com maiores similaridades sedimentológicas, permite abordagem mais detalhada, adequada ao entendimento da história evolutiva.

FÁCIES FAZENDINHA Sob a denominação fácies Fazendinha, são reunidos os depósitos coluviais identificados na Aloformação Manso, encontrados em discordância erosiva sobre os depósitos da unidade Cotiara. O nome Fazendinha é proveniente de uma localidade em que esses depósitos podem ser tipicamente reconhecidos.

A fácies Fazendinha corresponde a materiais areno-argilosos, amarelados, maciços, com freqüentes grânulos de quartzo, extremamente mal selecionados, micáceos, podendo ser subdivididos em duas camadas superpostas, informalmente designadas como Fazendinha I e Fazendinha II. Preservam restos vegetais carbonizados e comumente apresentam óxidos de ferro e de manganês. Atingem espessuras variáveis, em geral da ordem de alguns metros, existindo evidências de que podem localmente atingir cerca de $5 \mathrm{~m}$.

Os depósitos da fácies Fazendinha são identificados em relação de interdigitação com aqueles que constituem as fácies Campinho e Quebra-Canto, sendo comumente registrados próximo ao topo da Aloformação Manso. São tipicamente encontrados em baixa encosta.

Litologicamente, assemelham-se aos depósitos da Aloformação Cotiara, porém, mais grossos, sendo necessária análise estratigráfica detalhada para que possa ser identificado o limite descontínuo. Parecem resultar do retrabalhamento dos depósitos da unidade Cotiara.

FÁCIES QUEBRA-CANTO A denominação Quebra-Canto é proposta com o objetivo de individualizar depósitos de coloração arroxeada encontrados em notável discordância erosiva sobre a Aloformação Cotiara, podendo mesmo ser identificados em discordância erosiva sobre a unidade Rio do Bananal, ou ainda diretamente em inconformidade com o embasamento cristalino alterado. O nome Quebra-Canto é retirado de um curso fluvial situado próximo a uma das principais seções indicadas para representar a Aloformação Manso.

Esses depósitos são, caracteristicamente, arroxeados, texturalmente arenosos, areno-sílticos, areno-argilosos, muito mal selecionados, micáceos, feldspáticos. Encontram-se distribuídos em camadas tabulares centimétricas, mais ou menos contínuas, apresentando em sua totalidade espessuras da ordem de até $10 \mathrm{~m}$, podendo atingir espessuras maiores.

Uma característica significativa dos depósitos da fácies Quebra-Canto é que, enquanto se encontram distribuídos em camadas tabulares, de forma similar aos depósitos fluviais englobados na fácies Campinho, com os quais estão intimamente interdigitados, apresentam feições sedimentológicas próximas a dos depósitos coluviais, correspondendo a materiais de granulometria heterogênea, maciços, com freqüentes granules de quartzo; os níveis mais arenosos apresentam maior similaridade sedimentológica com depósitos fluviais, podendo ser observadas estratificacões plano-paralelas mal desenvolvidas. Isso levou esses depósitos a serem reconhecidos como aluvio-coluviais.

Outro fato importante é o reconhecimento de que os depósitos da fácies Quebra-Canto dispõem-se geometricamente sob 


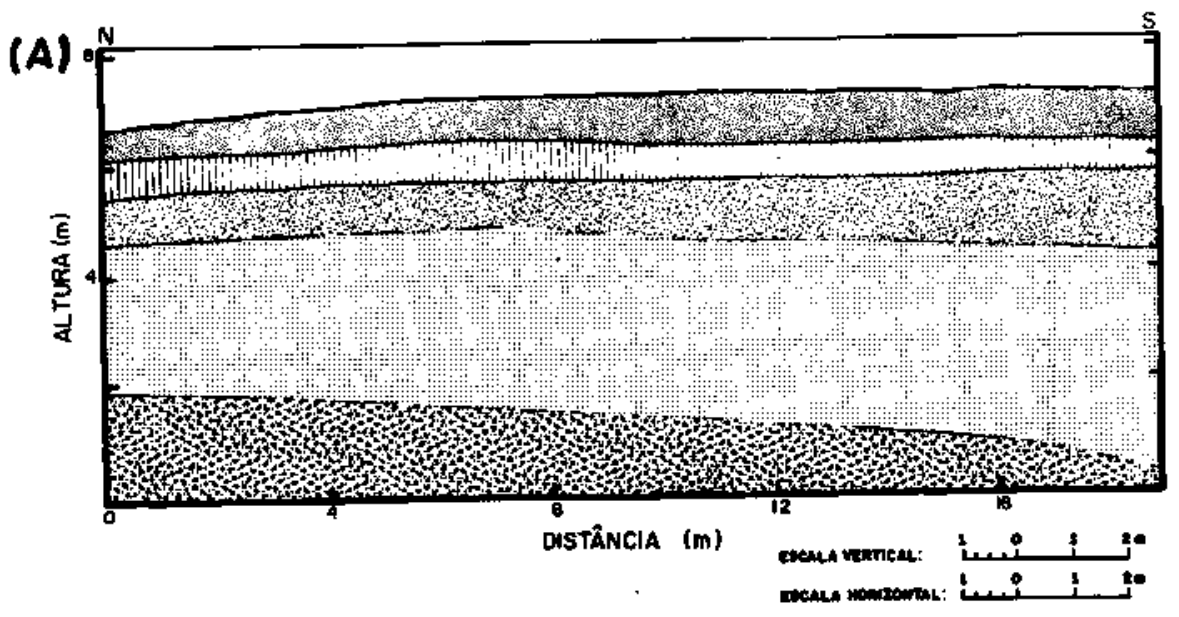

(B)

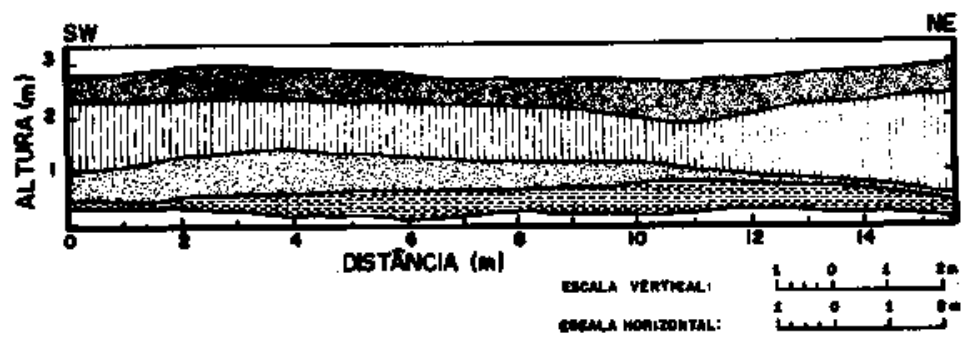

LEGENOA
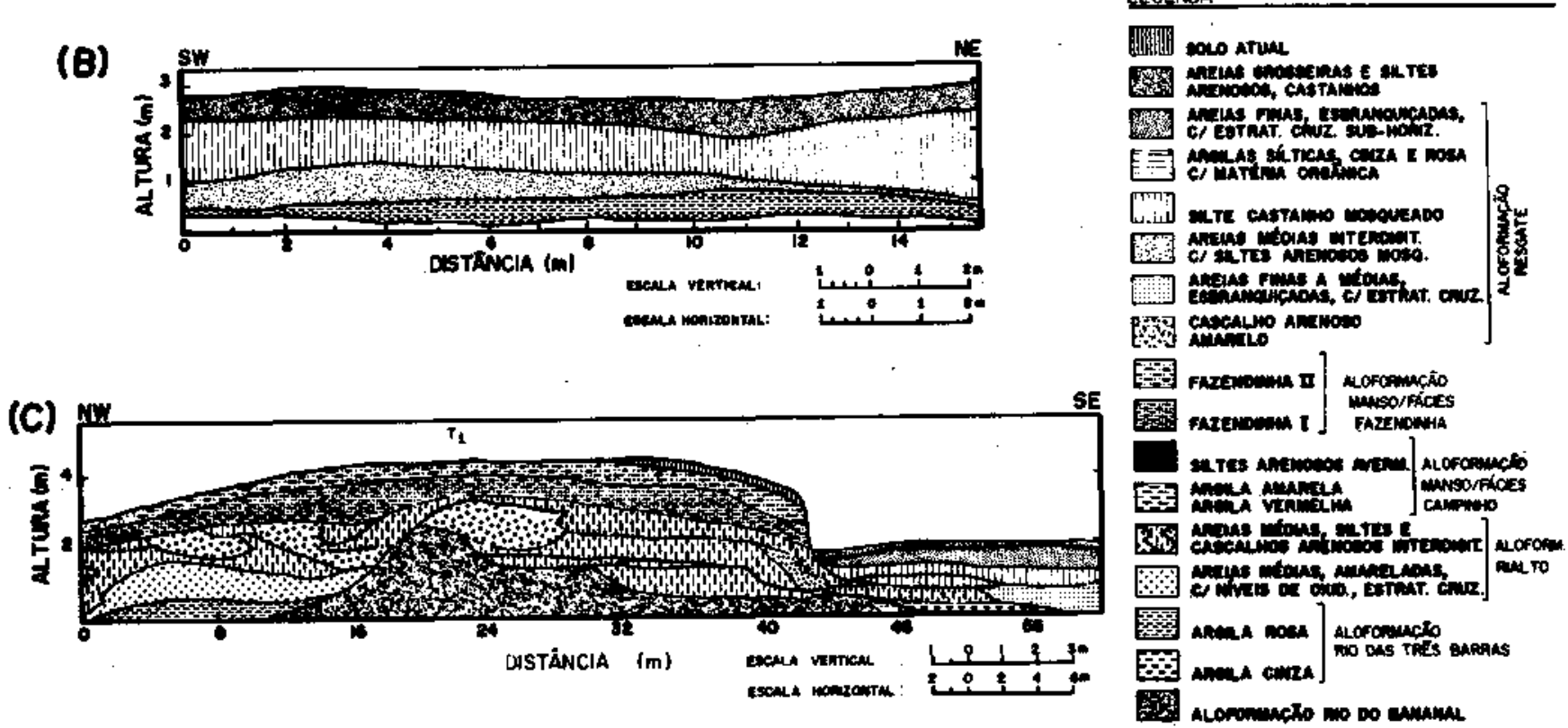

Alononacio no do caminat

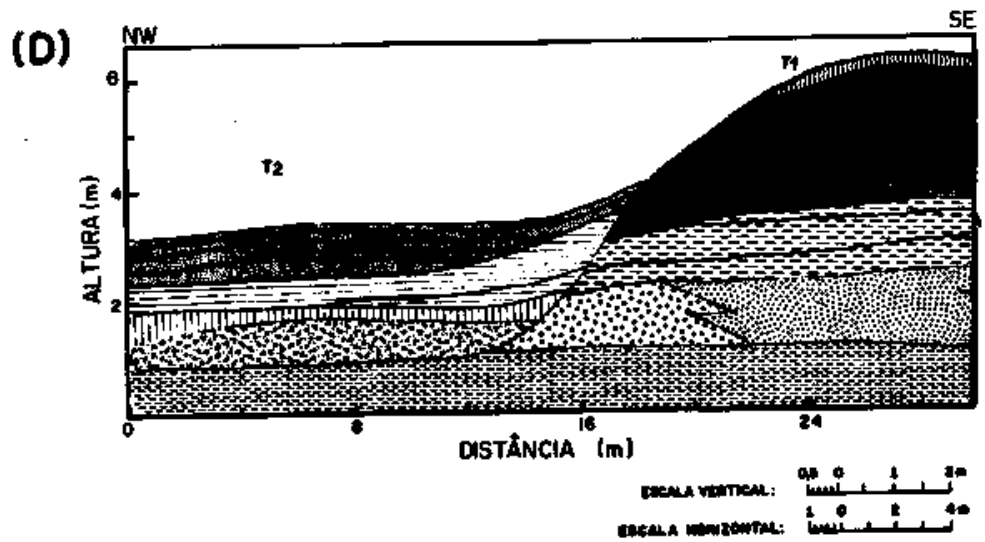

Figura 10 - A. Seção Rialio/T2, situada na estrada Bananal (SP) - Rialto (RJ), a $18 \mathrm{~km}$ de Bananal ao lado da ponte sobre o Rio do Bananal, na margem esquerda deste curso fluvial; B. Seção Cerâmica Joana D'Arc/72 localizada na rodovia SP-066, a 1,5 km de Bananal (SP), em terreno da antiga Cerâmica Joana D'Arc, a margem esquerda do Rio do Bananal; C. Seção Córrego do Resgaste III, localizada na margem direita do Córrego do Resgate, a aproximadamente 2,5 km a partir da SP-066, na área da Fazenda Fazendinha, a $13 \mathrm{~km}$ de Bananal (SP) rodovia; D. Seção Córrego do Resgate IV; localizada na margem direita do córrego do Resgate, a aproximadamente $3 \mathrm{~km}$ a partir da SP-066, na área da Fazenda Fazendinha,

Figure 10 - A Rialto/T2 Section Bananal; (SP) - Rialto (RJ) road, $18 \mathrm{~km}$ from Bananal, beside a bridge over Bananal river, on the left margin of this stream- B Cerâmica Joana D'Arc/T2 Section; SP-066, $1.5 \mathrm{~km}$ from Bananal, on the left margin of Bananal river, C. Córrego do Resgate III Section, Resgate creek right margin, $2.5 \mathrm{~km}$ from SP-066, $13 \mathrm{~km}$ from Bananal (Fazendinha Farm area); D. Córrego do Resgate IV Section, Resgate creek right margin,3 km from SP-066, $13.5 \mathrm{~km}$ from Bananal (Fazendinha Farm area) 


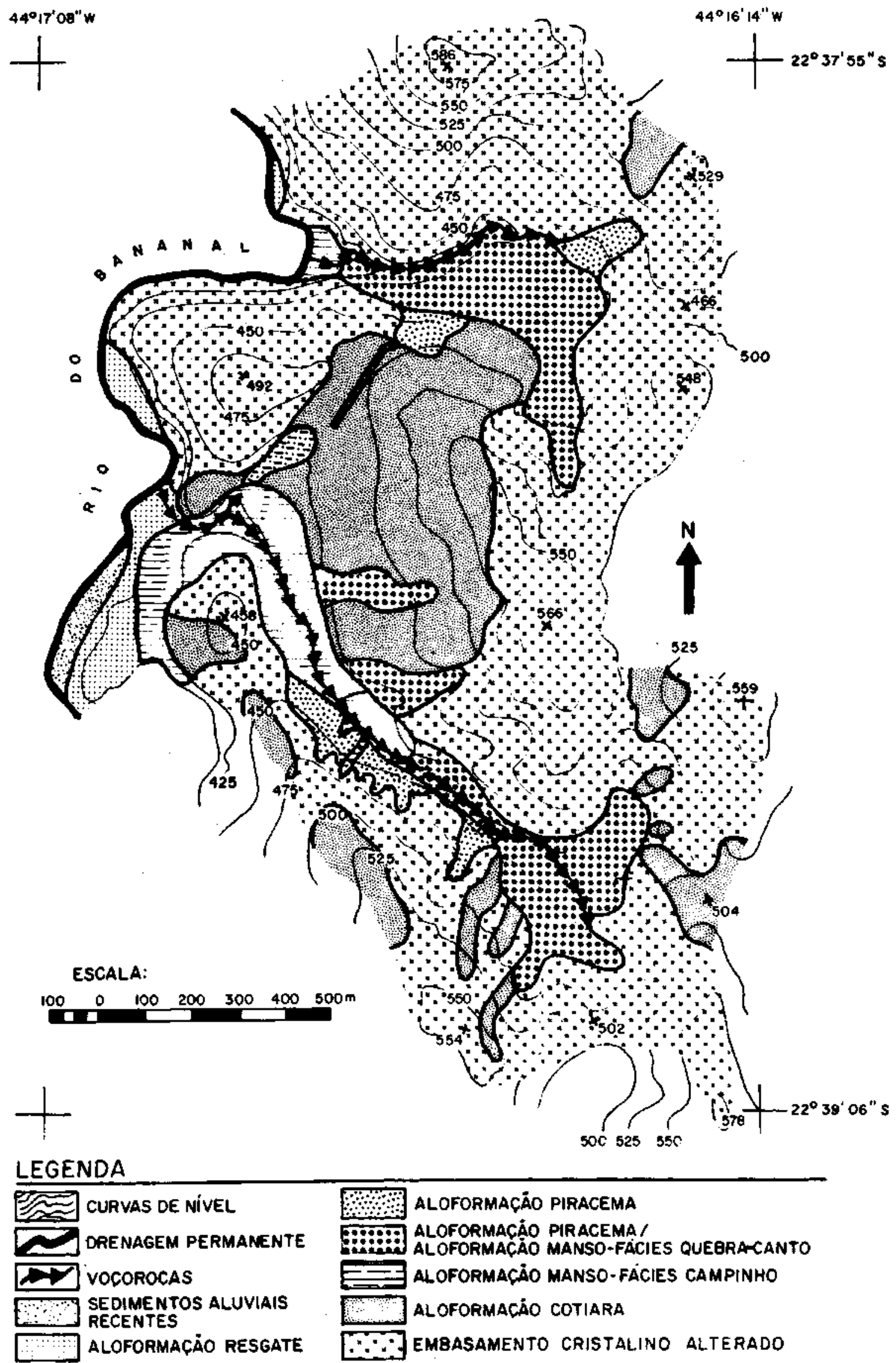

Figura 11 - Mapa das unidades aloestratígráficas em uma área do médio curso do Rio do Bananal (área da Fazenda Três Barras)

Figure 11 - Allostratigraphic map of a specific area in middle Bananal river valley (Três Barras Farm area) 


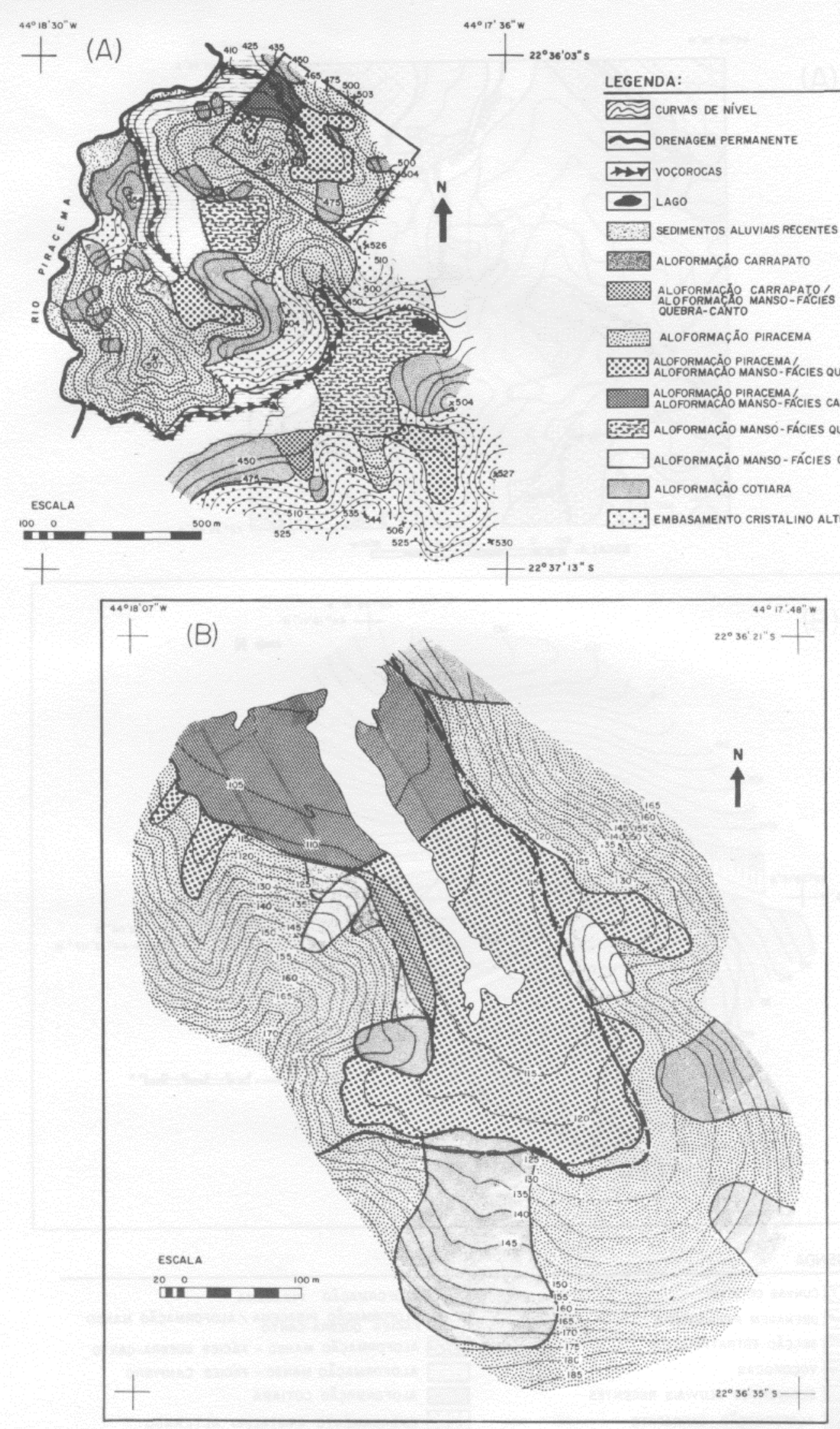

Figura 12 - A. Mapa das unidades aloestratigráficas em uma área do baixo curso do Rio Piracema (área da Fazenda Bela Vista); B. Mapa das unidades aloestratigráficas em uma cabeceira de drenagem no baixo curso do Rio Piracema (voçoroca da Fazenda Bela Vista) - detalhe do mapa anterior

Figure 12 - A. Allostratígraphic map of an specific area in lower Piracema river valley (Bela Vista Farm area); B. Allostratigraphic map of a headwater in lower Piracema river valley (Bela Vista farm farmgully) - detail from preceding map 

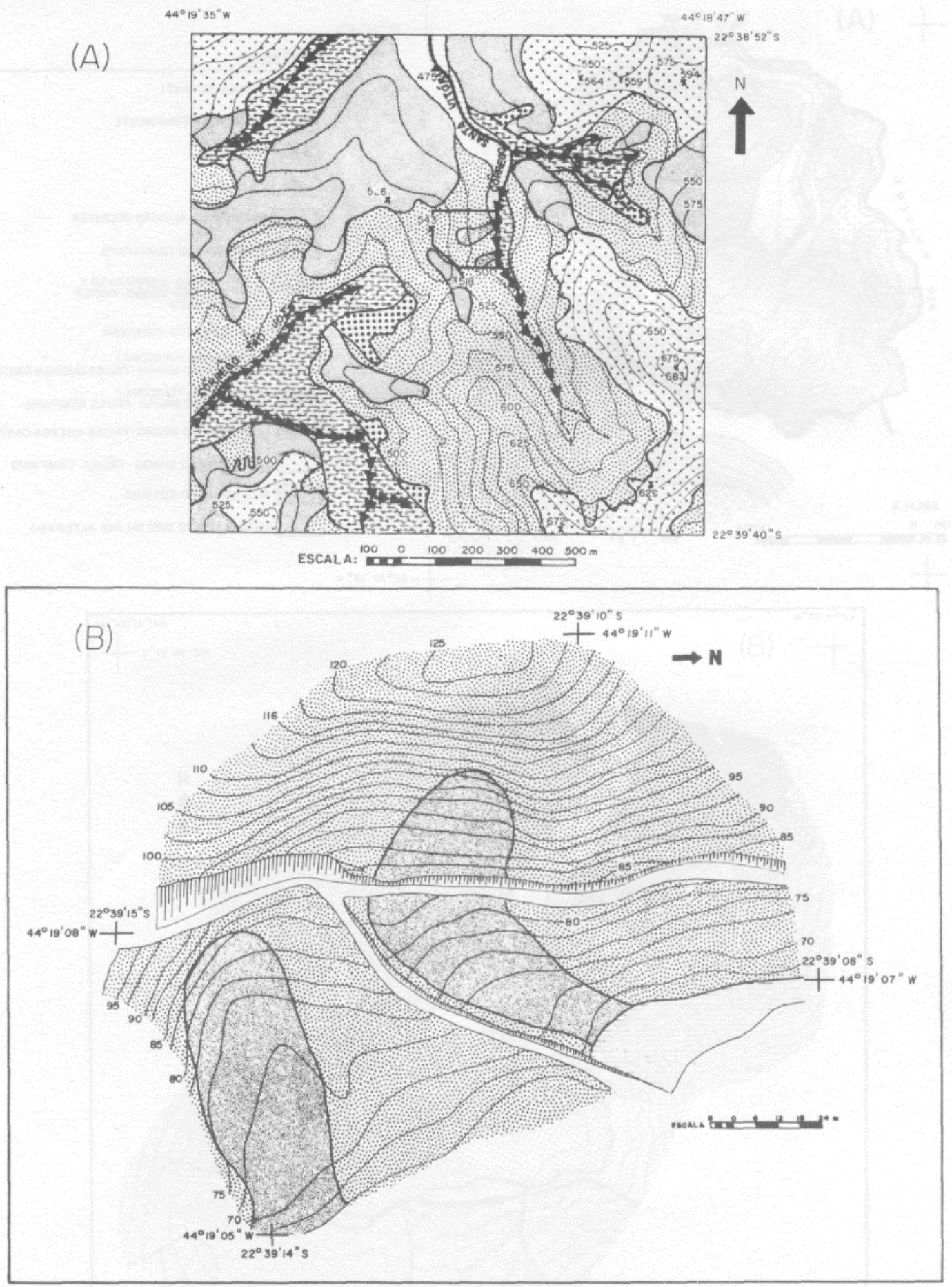

\section{LEGENDA}

J CURVAS DE NIVEL
DRENAGEM PERMANENTE
SECGÃO ESTRATIGRÁFICA

Figura 13-A. Mapa das unidades aloestratigráficas na localidade Treviso; B. Mapa das unidades aloestratigráficas no anfiteatro Treviso - detalhe do mapa anterior

Figure 13 - A. Allostratigraphic map of Treviso site; B. Allostratigraphic map of Treviso amphitheater - detail from preceding map 


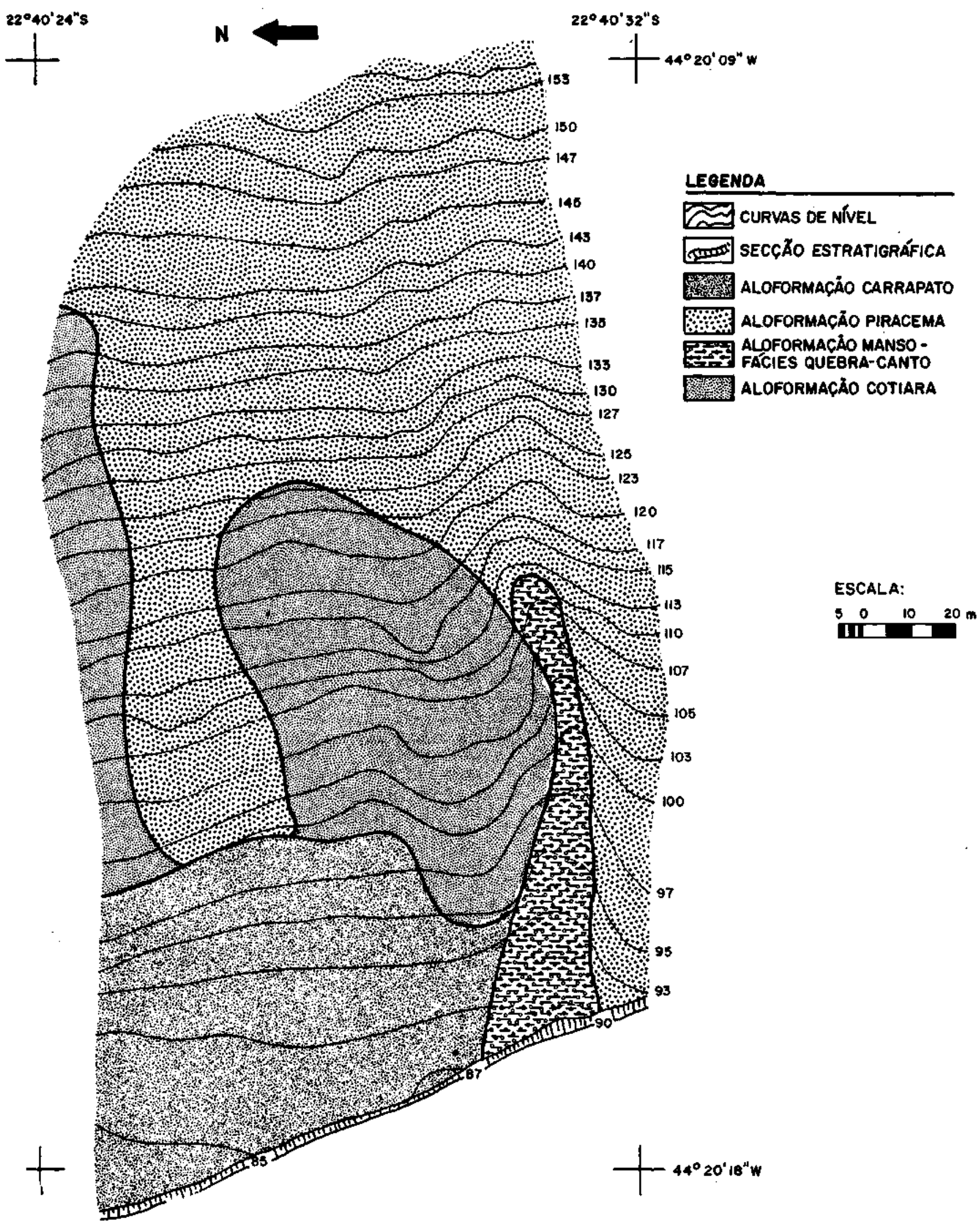

Figura 14 - Mapa das unidades aloestratigráficas no anfiteatro Bom Retiro Figure 14 - Allostratigraphic map of Bom Retiro amphitheater. 
a forma de canais que se prolongam desde o fundo dos vales até a média encosta, o que pode ser facilmente identificado pelas sondagens Bom Retiro (Fig. 5b) e Bela Vista (Fig. Tb).

Considera-se que a formação desses depósitos está relacionada a um evento de erosão linear acelerada (paleovoçorocas) de grande expressão regional, chegando a atingir, nas cabeceiras de drenagem, o embasamento cristalino alterado.

Os depósitos da fácies Quebra-Canto estão freqüentemente associados a anfiteatros que apresentam ruptura abrupta das encostas laterais com o fundo piano-horizontal a subonzontal das reentrâncias (hollows), correspondendo ao que Moura et al (1991) definem como HCP (anfiteatros com Hollow Côncavo-Plano). A identificação dessas feições geomorfológicas particulares e significativas na região considerada é importante no reconhecimento desses depósitos.

FÁCIES CAMPINHO A denominação Campinho é proposta para identificar os depósitos fluviais reconhecidos dentro da Aloformação Manso, caracterizados por heterogeneidade sedimentológica bastante significativa. A designação Campinho é proveniente de uma localidade onde esses depósitos fluviais podem ser tipicamente identificados.

Os sedimentos que compõem a fácies Campinho são comumente encontrados em discordância erosiva sobre os depósitos das unidades Rialto e Rio das Três Barras, estando representados nos terraços fluviais mais antigos (TI). Correspondem, muitas vezes, ao arcabouço sedimentar básico registrado em muitos vales fluviais da área de estudo.

Os depósitos da fácies Campinho da Aloformação Manso dispõem-se em camadas mais ou menos contínuas, geralmente horizontalizadas, com espessuras em torno de vários centímetros. Essas camadas demonstram composição textural variável de argilas sílticas a areias grossas, sendo freqüentes gradações verticais e laterais; são materiais muito mal selecionados, apresentando cores variadas.

Os níveis arenosos possuem granulometria variável de areias sílticas, geralmente amareladas ou avermelhadas, a areias grossas com cascalho, esbranquiçadas ou amareladas, podendo apresentar estratificações cruzadas bem desenvolvidas. São comuns níveis de oxidação e crostas ferruginosas. Mineralogicamente, são quartzosas, feldspáticas e micáceas.

As camadas de textura mais fina correspondem a argilas sílticas e siltes argilosos, amarelados, rosados ou arroxeados, comumente apresentando laminações horizontais milimétricas e níveis gradacionais centimétricos; são, caracteristicamente, micáceas, podendo preservar matéria orgânica em quantidade variável.

O topo da fácies Campinho é representado por uma seqüência de areias sílticas e siltes arenosos, avermelhados e amarelados, sem estruturas sedimentares visíveis, e micáceos.

Em sua totalidade, os depósitos da fácies Campinho apresentam espessuras registradas da ordem de até $10 \mathrm{~m}$, mas existem evidências indicativas de espessuras maiores.

Os depósitos que compõem a Aloformação Manso representam um importante marco estratigráfico dentro da seqüência deposicional neoquaternária identificada na região de Bananal (Moura \& Mello 1989). A unidade Manso parece registrar uma fase de grande instabilidade na paisagem durante o Holoceno, representada por intensa retomada erosiva nas cabeceiras de drenagem. A seqüência evolutiva que tem sido considerada destaca a grande expressão do fenômeno erosivo, que chegou a atingir o embasamento cristalino e produziu tal quantidade de sedimentos que superou a capacidade dos cursos fluviais em transportá-los, sendo progressivamente entulhados (fácies Campinho), elevando-se o nível de base e provocando a retenção dos materiais provenientes das encostas (fácies Quebra-Canto e Fazendinha) cada vez mais próximo às fontes de suprimento. $\mathrm{O}$ resultado final parece ter sido o entulhamento generalizado da paisagem, documentado em grande parte da região estudada.
Por sua importância dentro do quadro evolutivo e expressão regional os depósitos da Aloformação Manso são destacados nos mapeamentos efetuados (Figs. 11 a 14), recorrendo-se ao mapeamento por associação de unidades, quando registrados em subsuperfície.

Aloformação Piracema Sob a denominação Aloformação Piracema, são reunidos depósitos que constituem uma seqüência coluvial de grande expressão na região estudada, em nítida discordância erosiva sobre as unidades subjacentes. O nome é retirado do Rio Piracema, principal afluente do Rio do Bananal, e em cuja bacia estão localizadas muitas das seções estratigráficas apresentadas.

A seção Bom Retiro (Fig. 5a) é indicada para representar o estratótipo da unidade Piracema. As seções Treviso (Fig. 4a), Fazendinha (Fig. 6b), Três Barras (Fig. 6c), Cotiara (Fig. 7a), Rialto/Tl (Fig. 8a), Cerâmica Joana D'Arc/Tl (Fig. 8b), Campinho (Fig. 9a), Turvo (Fig. 9b) e Piracema (Fig. 9c) são indicadas como suplementares.

Os depósitos dessa unidade são mapeáveis em superfície, demonstrando a maior representatividade espacial entre as unidades definidas. Podem ser encontrados em diversas situações quanto à topografia das encostas, nos interflúvios, encostas laterais ou preenchendo as reentrâncias (hollows) dos anfiteatros, sendo registrados freqüentemente no topo dos terraços fluviais mais antigos (TI). Essas relações são documentadas nas sondagens Treviso (Fig. 4b), Bom Retiro (Fig. 5 b) e Bela Vista (Fig. Tb), assim como nos mapeamentos realizados (Figs. 11 a 14).

Podendo ser registrados em discordância erosiva sobre todas as unidades subjacentes, ou comumente em inconformidade com embasamento cristalino alterado, os depósitos da Aloformação Piracema são litologicamente caracterizados por materiais de granulometria variada, extremamente mal selecionados, subdivididos em duas camadas superpostas, separadas por descontinuidade textura!. A camada inferior é representada por depósitos argilo-arenosos, castanho-avermelhados, com freqüentes grânulos de quartzo; a camada superior diferencia-se por sua textura mais grossa, areno-argilosa, castanho-avermelhada, com granules de quartzo; ambas são maciças, apresentando estrutura pedológica em blocos, alcançando no total espessuras registradas da ordem de até $5 \mathrm{~m}$. Informalmente, são adotadas as denominações propostas por Moura \& Meis (1986) para a identificação das camadas que compõem a unidade Piracema, respectivamente Piracema I e II. Estudos recentes (Santos 1990) demostraram que as descontinuidades texturais apresentadas pelas camadas Piracema I e II correspondem a diferenciações pedológicas em horizontes de solo.

Os depósitos da Áloformação Piracema parecem registrar uma fase de grande atividade na dinâmica das encostas, resultando no retrabalhamento das unidades coluviais subjacentes, atingindo o embasamento cristalino e provocando o remodelamento da paisagem.

Aloformação Resgate Os depósitos fluviais que constituem o arcabouço estratigráfico básico registrado no nível intermediário de terraços fluviais (T2) são reunidos sob a denominação Aloformação Resgate, nome retirado de um curso fluvial afluente do Rio do Bananal - nessa bacia, os depósitos dessa unidade podem ser tipicamente reconhecidos.

As principais seções de referência escolhidas para representar os depósitos da unidade Resgate - seções-tipo - correspondem às seções Córrego do Resgate III (Fig. 10c) e Córrego do Resgate IV (Fig. 10d), sendo indicadas como suplementares à descrição as seções Rialto/T2 (Fíg. 10a) e Cerâmica Joana D'Arc/T2 (Fig. 10b).

A principal feição distintiva da Aloformaçíto Resgate corresponde à notável discordância erosiva que separa a unidade dos depósitos fluviais mais antigos, relacionada a eventos, 
dentro da dinâmica neoquatemária de evolução da paisagem, de entalhe erosivo dos canais fluviais e formação do nível intermediário de terraço fluvial (T2). Assim, os depósitos da unidade Resgate são encontrados em discordância erosiva nítida sobre as unidades Manso, Rialto e Rio das Três Barras, coincidindo o limite superior com o topo do terraço fluvial intermediário (T2), superfície geomorfológica que permite o reconhecimento da unidade. Deve ser ressaltado que, apesar de representarem o arcabouço sedimentar básico identificado no nível de terraço intermediário, os depósitos da unidade Resgate não correspondem ao registro sedimentar único dessa unidade geomorfológica, que pode englobar seqüências mais antigas (nível de terraço parcialmente erosivo e parcialmente de agradação).

A Aloformação Resgate é mapeável em superfície, porém não é encontrada em todos os subsistemas de drenagem da região, como pode ser verificado nos mapeamentos realizados (Figs. 11 a 14). Moura \& Mello (inédito) relacionam a descontinuidade espacial da unidade Resgate a condições particulares e significativas dentro da evolução dos sistemas de drenagem na região de Bananal.

litologicamente, os depósitos da unidade Resgate compõem-se de camadas areno-sflticas superpostas, com espessuras variáveis, atingindo em sua totalidade espessuras registradas de até $5 \mathrm{~m}$. Os depósitos identificados iniciam-se por uma camada de areias finas a grossas, de cores esbranquiçadas, amareladas e acastanhadas, micáceas, moderadamente selecionadas, mostrando estratificações cruzadas bem desenvolvidas, planares e acanaladas, apresentando cascalho arenoso na base, composto por seixos subarredondados a subanculosos de quartzo e fragmentos de rocha em matriz de areia grossa. Acima, caracteriza-se uma camada composta por areias finas a médias, acastanhadas, finamente estratificadas, micáceas, e níveis siltico-arenosos, castanhos, micáceos. Outra camada, sobreposta, é constituída por siltes castanhos apresentando certo mosqueamento, podendo preservar matéria orgânica (restos vegetais). São encontrados, também, níveis argilosos de coloração cinza e rosada, gradacionais, bastante orgânicos, micáceos. Completando os depósitos identificados na Aloformação Resgate, no topo dessa unidade, são observadas areias finas e sflticas, esbranquiçadas a acastanhadas, mostrando estratif icações cruzadas planares de baixo ângulo, muito micáceas e relativamente bem selecionadas.

Existe significativa similaridade litológica entre as areias que compõem as camadas inferiores da unidade Resgate e aquelas da Aloformação Rialto. A separação entre elas pode ser bastante difícil, principalmente se a distinção morfológica entre os níveis de terraço não for evidente. Análises mineralógicas que vêm sendo realizadas têm demonstrado que essas unidades podem ser individualizadas com base em relações composicionais de minerais leves e pesados.

O significativo enriquecimento em finos em direção ao topo da unidade Resgate pode ser uma evidência importante para a caracterização do ambiente fluvial relacionado, existindo a necessidade de um estudo faciológico mais detalhado que possa levar à identificação dos processos de sedimentação associados.

Aloformação Carrapato A última unidade individualizada na coluna estratigráfica proposta corresponde a uma seqüência coluvial definida sob a denominação Aloformação Carrapato. A designação geográfica é proveniente de um curso fluvial, componente da bacia do Rio Piracema, onde os depósitos da unidade Carrapato estão bem representados.

Para representar a unidade, foi escolhida como seção-tipo a Seção Bom Retiro (Fig. 5a), sendo indicada como suplementar à sua descrição a seção Treviso (Fig. 4a). Nas sondagens Treviso (Fig. 4b), Bom Retiro (Fig. 5b) e Bela Vista (Fig. Tb), pode ser observada sua distribuição nas encostas.
Os depósitos da unidade Carrapato são encontrados em discordância erosiva sobre as unidades coluviais subjacentes; são mapeáveis em superfície, demonstrando representatividade menor em relação às outras unidades identificadas, limitando-se a situações de baixa encosta, preenchendo reentrâncias (hollows) de anfiteatros.

A Aloformação Carrapato é litologicamente constituída por materiais areno-argilosos castanhos, com granules de quartzo, extremamente mal selecionados, maciços, apresentando estrutura pedológica incipiente, com espessuras registradas da ordem de um metro. Esses depósitos foram informalmente definidos com o colúvio Bela Vista por Moura \& Meis (1986).

A seqüência coluvial representada pela Aloformação Carrapato parece registrar uma fase mais recente de remodelamento das encostas, que seria o último dos principais eventos identificados nos depósitos quaternários encontrados na região de Bananal, para a dinâmica das encostas.

CONSIDERAÇÕES FINAIS A aloestratigrafia, como método de reconhecimento estratigráfico dos depósitos quaternários, toma possível a identificação de marcadores estratigráficos melhor reconhecidos e acompanhados do que qualquer outro aspecto litológico ou biológico presente, ressaltando o significado das descontinuidades estratigráficas dentro do registro sedimentar.

Ultimamente, a importância das descontinuidades na análise estratigráfica tem sido reconhecida e utilizada de modo mais amplo no tempo geológico, fundamentando propostas de individualização de seqüências sedimentares (Goodwin \& Anderson 1985, ISSC 1987). Considerando as novas categorias surgidas recentemente na nomenclatura estratigráfica, talvez a mais debatida entre essas seja aquela das unidades limitadas por descontinuidades (Owen 1987).

A frequêencia de descontinuidades estratigráficas observada na seqüência deposicional estudada, algumas vezes associadas à preservação de perfis completos de paleossolos, promove argumentos que sugerem a compartimentação do registro sedimentar considerado em uma sucessão de eventos de instabilidade e estabilidade dentro da evolução neoquaternária da paisagem.

No Pleistocene, a dinâmica evolutiva regional é documentada por depósitos coluviais representados em duas fases de retrabalhamento dos regolitos e remodelamento das encostas - Aloformação Santa Vitória e Aloformação Rio do Bananal. Essa última, apresentando um paleo-horizonte A datado em aproximadamente 10.000 anos (limite Pleistoceno/Holoceno), teria sido responsável pelo entulhamento dos vales pluviais, localmente represados, originando uma rede descontínua de pequenos lagos, cujo testemunho sedimentar é representado pelas argilas da Aloformação Rio das Três Barras, datadas em aproximadamente 9.500 anos (Moura \& Meis 1986).

A seqüência de eventos registra, a seguir, nova fase de remodelamento das encostas, representada pela Aloformação Cotiara. É provável que, contemporaneamente, tenha se instalado, nas calhas fluviais, o sistema de canais tipo braided documentado nos depósitos da Aloformação Rialto.

Uma fase de significativa instabilidade ambiental é registrada pelos depósitos da Aloformação Manso, nitidamente em discordância erosiva com as unidades subjacentes. Fenômenos de erosão linear acelerada promoveram o recuo das encostas por meio de um sistema de paleovoçorocas, produzindo tal quantidade de sedimentos que excedeu a capacidade dos cursos fluviais em transportá-los, resultando no completo entulhamento dos vales pluviais, ainda hoje preservado na grande maioria das bacias de drenagem regionais.

Depósitos coluviais subseqüentes promoveram um maior ou menor remodelamento da topografia das encostas - Aloformação Piracema e Aloformação Carrapato. Intercalada entre essas duas seqüências coluviais, a Aloformação Resgaste documenta outra fase de entalhe erosivo e posterior agradação 
dos canais fluviais. Tal evento, no entanto, ocorreu somente nos poucos sistemas de drenagem que acompanharam a evolução dos coletores principais.

As unidades limitadas por descontínuidade são, por definição, diacrônicas. Porém, é reconhecido que possuem um importante significado cronoestratigráfico, em função de as descontinuidades representarem um marco lateral. Faltam datações que permitam uma melhor definição do sentido temporal das unidades aloestratígráficas definidas. A quantidade de restos orgânicos observados deve possibilitar a obtenção de idades mais precisas para os depósitos considerados, assim como fundamentar estudos palinológicos de grande relevância.

Os depósitos neoquaternários identificados na região de Bananal (SP/RJ) apresentam significativa correlação com aqueles já estudados no médio vale do Rio Doce e em outras áreas do médio vale do Rio Paraíba do Sul (Meis 1977, Meis \& Monteiro 1979, Moura \& Meis 1980, Machado \& Moura 1982), com similaridades estratigráficas, morfo- lógicas de idade. Torna-se importante, assim, o estabelecimento de uma nomenclatura estratígráfica estável, provável de ser estendida a depósitos encontrados em outras regiões do Planalto Sudeste do Brasil.

Os argumentos apresentados no contexto metodológico deste trabalho visam dimensionar a importância da aloestratigrafia como básica às demais colunas estratigráficas do Quaternário Continental. Da mesma forma, constitui-se como suporte para o mapeamento das formações superficiais, útil ao desenvolvimento de projetos agrícolas e de controle da erosão, assim como à utilização racional dos recursos naturais.

Agradecimentos Esse trabalho não poderia ter sido desenvolvido sem o apoio financeiro da FINEP, CNPq, FAPERJ e CEPG/UFRJ, bem como sem a dedicada colaboração de todos os membros do Grupo de Estudos em Geomorfologia e Estratigrafia do Quaternário - GEOQUAT (IGEO/UFRJ). Desejamos agradecer ao Prof. Josué Camargo Mendes por suas relevantes sugestões e pela revisão critica do artigo.

\section{REFERÊNCIAS BIBLIOGRÁFICAS}

ALMEIDA, EF.M.; HASUI, Y; PONÇANO, W.L.; DANTAS, A.S.L.; CARNEIRO, C.D.R.; MELO, M.S.; BISTRICffl, CA. 1981. Mapa Geológico do Estado de São Paulo. São Paulo, IPT. 126 p. (Série Monografias 6).

ASMUS, H.E. \& FERRARI, A.L. 1978. Hipótese sobre a causa do tectonismo cenozóico na região Sudeste do Brasil. Li: PETROBRÁS. Aspectos estruturais da margem continental leste e sudeste do Brasil. Rio de Janeiro, CENPES/DINTEP. p. 75-88. (Série Projeto REMAC 4).

BIGARELLA, J.J. \& ANDRADE, G.O. 1965. Contribution on the study of Brazilian Quaternary. INTERNATIONAL STUDIES ON THE QUATERNARY. Boulder, Colorado. Geol. Soc. Am. Spec. Pap., 84, p. 433-451.

BIGARELLA, J.J.; MOUSINHO, M.R.; SILVA, JX. 1965. Pediplanos, pedimentos e seus depósitos correlatives no Brasil. Boi. Parana. Geogr. 16/17:117-151.

BOWEN, D.Q. 1978. Quaternary Geology: a Stratigraphic Framework for Multidisciplinary Work London, Pergamon Press. 22 Ip.

COMISSÃO ESPECIAL DE NOMENCLATURA ESTRATIGRÁFICA/SBG 1986. Código Brasileiro de Nomenclatura Estratígráfica. Rev. Bras. Geoc., 16(4):370-415

FAIRBRIDGE, R.W. 1968. Quaternary Period. In: FAIRBRIDGE, R.W. ed. Encyclopedia of Geomorphology.. New York, Reinhold Book Co. p. 912-931.

FRYE, J.C. \& WILLMAN, H.B. 1962. Morphostratigraphic Units in Pleistocene Stratigraphy. Am. Assoc. Pet. Geol. Bull, 46:112-113.

GOODWIN, P.W. \& ANDERSON, E.J. 1985. Punctuated Aggradational Cycles: a general hypothesis of episodic Stratigraphic accumulation. $J$. Geology, 93(5):515-533.

HASUI, Y; PONCCANO, W.L.; BRISTICHL C.A.; STEIN, D.P.; GALVÃO, CA.CF.; ALMEIDA, M.A.; PIRES NETTO, A.G.; MELO, M.S.; SANTOS, M.C.S.R. 1978. Geologia da Região Administrativa 3 (Vale do Paraiba) e pane da Região Administrativa 2 (Litoral do Estado de São Paulo). São Paulo, IPT. 78 p. (Série Monografias 1).

INTERNATIONAL SUBCOMMISSION ON STRATIGRAPHIC CLASSIFICATION 1987. Unconformity-bounded Stratigraphic units. Geol. Soc. Am. Bull, 98:232-237.

MACHADO, M.B. \& MOURA, J.R.S. 1982. A geomorfologia e a sedimentacão quaternária no médio vale do Rio Casca, MG. In: CONOR BRAS. GEOL., 32. Salvador, 1982. Anais... Salvador, SBG. v. 4, p. 1433-1441.

MEIS, M.R.M. 1977. As unidades morfoestratigráficas neoquaternárias do médio vale do Rio Doce. An, Acad bras. Cienc. 49:443-459.

MEK, M.R.M. \& MONTEIRO, A.M.F. 1979. Upper Quaternary "Rampas", Doce River Valley, SE Brazilian Plateau. Z. Geomorphol, 232:132-151.
MEIS, M.R.M. \& MOURA, J.R.S. 1984. Upper Quaternary Sedimentation and Hillslope Evolution: Southeastern Brazilian Plateau. Am. J. Sci., 284:241-254

MEIS, M.R.M.; MOURA, J.R.S.; SILVA, T.J.O. 1981. Os "complexos de rampa" e a evolucão das encostas no Planalto SE do Brasil. An. Acad. bras. Ciênc., 53(3):605-615.

MENDES, J.C. 1984. Aspectos da estratigrafia do Quaternário. In: QUEIROZ, T.A. ed. Elementos de Estratigrafia. São Paulo, EDUSP. p. 468-496.

MIALL, A.D. 1977. A review of the braided river depositional environment Earth. Sci. Rev. 13:1-62.

MOURA, J.R.S. \& MEIS, M.R.M. 1980. Litoestratigrafia preliminar para os depósitos de encostas do Quaternário Superior do Planalto SE doBrasil, MG-RJ. Rev. Bras. Geoc., 10(4):258-267.

MOURA, J.R.S. \& MEIS, M.R.M. 1986. Contribuicão à estratigrafia do Quaternário Superior no médio vale do Rio Paraíba do Sul - Bananal, SP. An. Acad. bras. Ciênc., 58(1):89-102.

MOURA, J.R.S. \& MELLO, CL. 1989. Aloformação Manso: um episódio de instabilidade ambiental no Holoceno do Planalto SE do Brasil. In: CONOR. BRAS. PALEONT., 11. Curitiba, 1989. Anais... Curitiba, SBP. V.Z, p. 1073-1083.

MOURA, J.R.S.; PEIXOTO, M.N.O.; SILVA, T.M. Geometria do relevo e estratigrafia do Quaternário como base à tipologia de cabeceiras de drenagem em anfiteatro - médio vale do Rio Paraíba do Sul. Rev. Bras. Geoc., 21(3):255-265.

NORTH AMERICAN COMMISSION ON STRATIGRAPHIC NOMENCLATURE 1983. North American Stratigraphic Code. Am. Assoc. Pet. Geol Bull, 76(5):841-875.

OWEN, D.E. 1987. Usage of Stratigraphic terminology in papeis, illustrations, and talks. J. Sediment. Petrol, 57(2):363-372.

PESSOA, M.Z.C. 1987. Subsídios à Bioestratigrafla do Quaternário Superior no Planalto Sudeste do Brasil, Região de Bananal-SP: Estudo Preliminar. Rio de Janeiro. 94 p. (Dissertação de Mestrado, IGEO/UFRJ).

PONCANO, W.L; CARNEIRO, C.D.R.; BISTRICHI, CA.; ALMEIDA, F.F.M.; PRANDINL F.L. 1981. Mapa Geomorfológico do Estado de São Paulo. São Paulo, IPT. 94 p. (Série Monografias 5).

SANTOS, A.A.M. 1990. Evolução Pedo-Geomorfológica das Seqüências Coluviais Neoquaternárias, Bananal (SP). Rio de Janeiro, 234 p. (Dissertação de Mestrado, IGEO/UFRJ).

MANUSCRITO A638

Recebido em 2 de janeiro de 1990

Revisão do autor em 3 de agosto de 1990 Revisão aceita em 9 de agosto de 1990 